NBER WORKING PAPER SERIES

\title{
ARE POOR INDIVIDUALS MAINLY FOUND IN POOR HOUSEHOLDS? EVIDENCE USING NUTRITION DATA FOR AFRICA
}

\author{
Caitlin S. Brown \\ Martin Ravallion \\ Dominique van de Walle \\ Working Paper 24047 \\ http://www.nber.org/papers/w24047 \\ NATIONAL BUREAU OF ECONOMIC RESEARCH \\ 1050 Massachusetts Avenue \\ Cambridge, MA 02138 \\ November 2017
}

The authors are grateful to the World Bank's Strategic Research Program for funding assistance. Helpful comments were received from Harold Alderman, Arthur Alik-Lagrange, Denis Cogneau, Emanuela Galasso, Sylvie Lambert, Kate Rybczynski, Adam Wagstaff and seminar participants at Georgetown University, the University of California Riverside, the Paris School of Economics, University of Guelph, and the IEA World Congress in Mexico. These are the views of the authors and need not reflect those of their employers. The views expressed herein are those of the authors and do not necessarily reflect the views of the National Bureau of Economic Research.

NBER working papers are circulated for discussion and comment purposes. They have not been peer-reviewed or been subject to the review by the NBER Board of Directors that accompanies official NBER publications.

(C) 2017 by Caitlin S. Brown, Martin Ravallion, and Dominique van de Walle. All rights reserved. Short sections of text, not to exceed two paragraphs, may be quoted without explicit permission provided that full credit, including $\odot$ notice, is given to the source. 
Are Poor Individuals Mainly Found in Poor Households? Evidence using Nutrition Data for Africa

Caitlin S. Brown, Martin Ravallion, and Dominique van de Walle

NBER Working Paper No. 24047

November 2017

JEL No. I14,I32,I38

\section{ABSTRACT}

Antipoverty policies assume that targeting poor households suffices in reaching poor individuals. We question this assumption. Our comprehensive assessment for sub-Saharan Africa reveals that undernourished women and children are spread widely across the household wealth and consumption distributions. Roughly three-quarters of underweight women and undernourished children are not found in the poorest $20 \%$ of households, and around half are not found in the poorest $40 \%$. Countries with higher undernutrition tend to have higher shares of undernourished individuals in non-poor households. The results are consistent with intra-household inequality but other factors also appear to be at work including common health risks.

Caitlin S. Brown

Department of Economics

Georgetown University

cb575@georgetown.edu

Martin Ravallion

Department of Economics

Georgetown University

cb575@georgetown.edu
Dominique van de Walle

World Bank

1818 H Street NW

Washington DC 20433

dvandewalle@worldbank.org 


\section{Introduction}

While it is widely appreciated that poverty is an individual deprivation, household aggregate data are almost invariably used to infer individual poverty. It is assumed that each individual within the household has the same level of economic welfare as measured by household aggregate consumption per person (or per equivalent single adult). An array of antipoverty programs are targeted on this basis, typically using readily available proxies for household consumption or income per person. ${ }^{2}$ Partly in response to concerns about chronic undernutrition in certain regions, including in Africa, there is an expanding effort at social protection in developing countries and this effort is typically focused on transfers targeted to poor families. ${ }^{3}$ For its part, the World Bank has made reaching poor families—as often identified by the poorest two quintiles of people based on household consumption per person-the main objective of its social protection operations.

Three main reasons can be identified as to why the idea of reaching deprived individuals using antipoverty programs that explicitly target poor households is attractive to policy makers. First, there is a data constraint, namely that standard data sources do not allow us to measure individual consumption. Second, interventions at the individual level may be seen to be paternalistic and intrusive (as they require intervention within families) and may well be costly (to the extent that they rely on fine targeting, constrained by the fact that individual deprivations are not comprehensively observed in large populations). Third, in supporting this idea, an appeal can be made to a large literature that has documented that poorer households in terms of consumption, income or wealth are more likely to include deprived individuals. ${ }^{4}$ Aggregate household resources constrain consumption for all household members. For these reasons, it is not surprising that, in practice, many social policies hope to reach deprived individuals by targeting seemingly poor households.

However, the existence of a household wealth effect on individual welfare does not imply that targeting poor households will be very effective in reaching poor individuals. One can point to empirical evidence casting doubt on that assumption, including the evidence that rejects a unitary model of the household, suggesting there are sources of inequality within households that have been "assumed away"

\footnotetext{
${ }^{2}$ On these programs in developing countries see Coady et al. (2004), Fiszbein and Schady (2010), Ruel et al. (2013), Del Ninno and Mills (2015), and Ravallion (2016, Chapter 10).

${ }^{3}$ For evidence on the expansion in social protection programs in developing countries see Ravallion (2016, Chapter 10).

Various case studies of these programs in Africa are found in Del Ninno and Mills (2015).

${ }^{4}$ The evidence is reviewed in Ravallion (2016, Chapter 7). The present paper will return to the literature.
} 
in much past thinking about antipoverty policies. ${ }^{5}$ There is also evidence of discrimination against certain household members such as orphans and widows and the evidence of unequal exposure to transitory shocks. Heterogeneity in factors influencing individual poverty can also mean that transfers to poor households often miss deprived individuals. It is important for policy makers to know whether standard household data sources can be relied upon to reach poor individuals.

This paper tries to throw light on how well widely-used household-based measures perform in identifying disadvantaged individuals. Are we reaching such individuals adequately by simply targeting "poor” households? Or do many of them live in households that are not identified as poor? Is it harder or easier to reach vulnerable women and children using household data in poor-country settings in which the incidence of individual level disadvantage is high and average income is low?

Missing data on individual-level poverty present a significant hurdle to examining these issues. However, there is one important dimension of individual welfare that can be observed in many surveys, namely nutritional status as indicated by anthropometric measures. Undernutrition can stem from inadequate caloric intakes or deficiencies in protein or micronutrient intakes, or from illness that impedes nutritional absorption. Such nutritional deprivations are of direct and immediate concern, and there is also evidence of longer-term social and economic costs, especially of low-birth weight and chronic undernutrition in childhood. Although nutritional status admittedly represents only one dimension of individual poverty there can be no doubt that it is an important dimension. It is also frequently used as a proxy for individual welfare (Steckel 1995).

The paper uses undernutrition as the measure of individual welfare to explore the questions posed above. We use data for 30 countries in sub-Saharan Africa (SSA), where chronic undernutrition among children is a major policy concern. The latest data at the time of writing indicate that the count of stunted children in SSA has risen by 12.5 million since 1990. The incidence of child stunting in SSA today is probably the highest of any of the standard geographic groupings of countries. ${ }^{6} \mathrm{We}$ draw on anthropometric data for 390,000 women and children from the Demographic and Health Surveys (DHS). These data can be used to identify nutritionally vulnerable women and children. The DHS also include a household wealth index based on a household's assets and living conditions. We use this index as a proxy for household wealth. However, aggregate consumption may well be a better indicator of

\footnotetext{
${ }^{5}$ We elaborate on these points later and provide references to the literature.

${ }^{6}$ These observations are from the World Bank's website on nutrition and the latest available estimates compiled by UNICEF. Historically, South Asia has been the region with highest incidence but that region has been making greater progress than SSA in this respect. See the discussion in Smith and Haddad (2015). Differences in population growth also affect this shift to SSA of the global share of the undernourished.
} 
household welfare than the DHS wealth index, which (for example) may not respond quickly to shocks. We complement the DHS data with good-quality nationally-representative household consumption surveys from the World Bank's Living Standards Measurement Study (LSMS).

We acknowledge that nutritional status is not all that matters to individual welfare; our findings may not hold for other dimensions of individual poverty. Yet, in the absence of better individual poverty measures, and given considerable evidence of unequal intra-household allocation of resources, it is important to investigate this issue. Our results are also relevant to policy makers who are specifically interested in addressing health deprivations associated with undernutrition. There are various forms of direct interventions with the aim of improving nutrition, including direct nutrition supplementation and promoting better health practices. ${ }^{7}$ Many of these are implemented through health clinics and delivery points other than the household. However, there is a growing interest in doing so through householdbased policies - by integrating nutrition programs within anti-poverty policies more broadly. We throw light on whether this might work well.

Our principle finding is that, although the incidence of undernutrition tends to be higher in poorer households, nutritional deprivations are spread quite widely through both the wealth and consumption distributions, such that the joint probability of being an underweight woman or child and living in the poorest household wealth quintile is low. We find that about $75 \%$ of underweight women and undernourished children are not found in the poorest $20 \%$ of households, and half are not found in the poorest $40 \%$. This pattern is less pronounced but still holds when we use an augmented regression to control for various individual- and household-level factors which may influence nutritional outcomes. Our results point to the need for broad coverage in efforts to address undernutrition and, by extension, individual poverty, rather than subsuming this problem within antipoverty interventions that are targeted at the household-level. Data availability limits how far we can go in explaining our findings, but we point to evidence suggesting that intra-household inequality and common health risks are important factors.

The following section considers relevant arguments and evidence from the literature. Section 3 outlines a simple theoretical model to help understand the relevant aspects of the joint distribution of household poverty and individual undernutrition. Section 4 then reviews the data we shall be using. Section 5 presents the main findings, while Section 6 discusses various possible explanations for our results. Section 7 concludes.

\footnotetext{
${ }^{7}$ See for example the package of nutritional interventions described in Bhutta et al. (2013).
} 


\section{Insights from the literature}

A body of research on the economics of the household has focused on the wealth effect on nutritional status, i.e., how much nutrition improves as a household's economic welfare-income, consumption or wealth—rises. One strand of this literature has estimated income elasticities of demand for food and (hence) nutrition; an influential early example is Behrman and Deolalikar (1987). Rather than focus on food consumption, as in consumer demand studies (such as Pitt, 1983), other work has instead studied the income effect on nutritional adequacy, taking account of requirements for good health and normal activities in society. A low income-elasticity of demand for food can be consistent with a high responsiveness of nutritional adequacy to income gains, since even small gains in nutritional intakes can make a big difference at low levels (Ravallion 1990, 1992). ${ }^{8}$

New evidence on this topic has emerged from analyses of the many micro data sets (including the DHS) that have become available to researchers over the last 20 years or so. A limitation of the DHS is that the surveys have not included the questions needed to measure consumption or income. (At the same time, most surveys of the LSMS-type have not included anthropometrics.) The DHS wealth index was developed to help address this deficiency (Filmer and Pritchett 2001). Some studies have argued that the DHS wealth index is a good predictor of various human capital and other outcomes (Filmer and Pritchett 1999, 2001; Filmer and Scott 2012; Sahn and Stifel 2003; Petrou and Kupek 2010). For example, on comparing DHS wealth indices, Filmer and Scott (2012, p. 359) conclude that “...inferences about inequalities in education, health care use, fertility and child mortality, as well as labor market outcomes, are quite robust.” Similarly, Sahn and Stifel (2003, p. 463) argue that their version of the wealth index "...is a valid predictor of a crucial manifestation of poverty—child health and nutrition." Some other studies have been less supportive and have found only seemingly modest correlations between nutritional, health and other outcomes and wealth indices (Hong and Hong 2007; Zere and McIntyre 2003; Howe et al. 2009). Different data sets tell different stories here, so a comprehensive look at the evidence across multiple countries is needed.

A strand of the literature has used the DHS wealth index to measure inequalities in child nutritional status, mainly using the concentration curve which (in this context) gives the share of undernourished children living in the poorest $\mathrm{x} \%$ of households based on the wealth index (Kakwani et

\footnotetext{
${ }^{8}$ While it is not an issue taken up here, it is now well recognized that nutritional intakes can also be too high from the point of view of good health and normal activity levels. A strand of the literature has focused on obesity and its relationship to wealth in both rich and poor countries; for a review see Ravallion (2016, Chapter 7).
} 
al. 1997; Wagstaff and Watanabe 2000; Wagstaff et al. 2014; Bredenkamp et al. 2014). ${ }^{9}$ A widely-used measure based on this curve is the concentration index, given by twice the area between the curve and the diagonal (analogous to the Gini index). A key finding from this literature is that the concentration indices for child stunting and wasting in developing countries are almost invariably negative. A typical conclusion is that "Unsurprisingly, in all countries, undernutrition is concentrated among the poor." (Bredenkamp et al. 2014, p.1330).

Such assessments appear to support the common, but often implicit, assumption among social policy makers that targeting poor households will be effective in reaching undernourished individuals. However, our review of the literature suggests that the concentration indices are rarely more negative than -0.3 , with median values typically around -0.15 to -0.10 (depending on the measure of undernutrition). ${ }^{10}$ While this confirms that children from wealthier households tend to be better nourished (given that the index is negative), it also suggests that there is quite wide dispersion of undernutrition across wealth strata.

We also need to be aware of potential bias in anthropometric statistics that may affect the degree to which undernourished children are found to be concentrated in the poorest households. Two main factors can be noted. Excess mortality among malnourished children is well-established and may lead to a survivorship bias (Boerma et al. 1992; Bozzoli et al. 2007; Moradi 2010). If the deceased belonged to poor households, then the bias will result in a lower wealth gradient than would otherwise be the case. Against that, a negative association between the number of children and child nutritional status has also been documented (Desai 1995). Given that poorer households tend to have more children, this would instead lead to a larger concentration of malnourished children in poor households and a steeper wealth gradient.

A number of recent papers review the existing evidence on the nutritional impacts of income growth and income support to poor households. On the first, as already noted, several papers find seemingly low income effects, particularly in the short-term (Grogan and Moers 2016; Haddad et al. 2003; Smith and Haddad 2015). With respect to the second, Alderman (2015) and Ruel and Alderman (2013) conclude that social safety nets targeting poor households with food or cash transfers (whether conditional or unconditional) have generally had limited impacts on children's nutritional status. The papers speculate that this may be because the targeted households are not those that have young children

\footnotetext{
9 There has been far less focus on inequalities in malnutrition among women.

${ }^{10}$ The online Addendum to Bredenkamp et al. (2014) provides concentration indices across 80 developing countries for child undernutrition using the wealth index as the ranking variable. The median for stunting is -0.15 .
} 
in the right age range. They do not question the practice of targeting poor households to reach undernourished individuals. Manley et al. (2013) undertake a systematic review and meta-analysis on conditional and unconditional cash transfers and child nutrition and come to similar conclusions.

The existence of intra-household inequality is clearly relevant. The unitary model of the household (characterized by a single utility function) has found little support empirically, and various alternatives have been proposed (as recently reviewed by Chiappori and Mazzocco 2015; and Baland and Ziparo 2017). These models point to sources of inequality within households, such as in reservation utility levels, that will limit the scope for reaching poor individuals by targeting poor households. An extensive literature details intra-household inequalities in resource allocations and outcomes (as reviewed in World Bank 2012). There are two policy implications: targeting poor households may well miss some significantly disadvantaged individuals and targeted households may not allocate the benefits to the neediest within the household.

It is well recognized in principle that household-level consumption or income-based measures don't allow for inequality within the household. There is also (largely qualitative) evidence that certain individuals are poor and/or vulnerable, but do not live in households that would normally be considered poor and so are hidden from view in standard data sources on poverty. Differentiation between men and women has been widely documented in human capital, legal protection, constraints stemming from social norms, roles and responsibilities, and control over resources (Ezememari et al. 2002). For Africa, there is evidence that household shocks affect men and women differentially, with women bearing the brunt of negative shocks (Dercon and Krishnan 2000). Such differentiation can be expected to have consequences for measures of poverty and inequality. In an important early example, Haddad and Kanbur (1990) find that such measures for the Philippines are appreciably underestimated using standard household-level data, although the "profiles"- comparisons of these measures across subgroups such as urban and rural areas-are quite robust. Using a survey for Senegal that (unusually) collected a relatively individualized measure of consumption, Lambert et al. (2014) find significant inequalities within the household and a sizeable gender gap in consumption. Using the same data, De Vreyer and Lambert (2016) estimate that about one in eight poor individuals live in non-poor households. Using anthropometric data, Sahn and Younger (2009) find that about half of country-level inequality in the body mass index is within households rather than between them.

Other work has emphasized the poverty of specific types of individuals. Recent research on Mali confirms that widows - most of whom are absorbed into male headed households and can be quite 
young-experience significantly lower levels of individual (non-income) welfare indicators than women of other marital statuses, and that the disadvantage persists through remarriage (van de Walle 2013). Similarly, there is a large literature on orphans in the context of AIDS deaths, and the disadvantages they may face, particularly in schooling (Bicego et al. 2003; Case et al. 2004; Evans and Miguel 2007). There is also evidence to suggest a strong relationship between maternal and child health, with children found to be more susceptible to adverse shocks if they are borne by women in poorer health (Bhalotra and Rawlings 2011; 2013). While it may well be more likely that these disadvantaged groups live in relatively poor households, they may also be spread quite widely across the wealth distribution.

There are other sources of heterogeneity in individual health and nutrition at given levels of household wealth. Wagstaff (2003) finds large differences across developing countries in the incidence of underweight and stunted children even if one controls for wealth. Wagstaff also found that these differences are negatively correlated with public health spending per capita. This is consistent with other findings suggesting that cross-country differences in public health spending matter more for the poor than for others (Bidani and Ravallion 1997); the well-off are better able to protect their children's nutrition and health status from weak public provisioning and poor health environments. However, the powerful role of complementarities and externalities in water, sanitation and hygiene means that the better off also remain vulnerable to these deficiencies (Duflo et al. 2015; Ngure et al. 2014). Crosscountry comparisons of stunting incidence have also pointed to the role played by access to healthrelated infrastructure (such as water and sanitation facilities) in addition to household characteristics such as food availability and maternal schooling (Smith and Haddad 2015). Spears (2013) argues that differences in rates of open defecation explain much of the variation in child height across countries.

In the light of these studies, prevailing methods of measuring poverty and designing antipoverty policies using the household as the unit of observation may be inadequate. Economists and policymakers have traditionally looked at poverty and vulnerability using the household as the unit of observation. The gold standard for measuring poverty has long been household-based consumption normalized for household size and (possibly) demographic composition. In the absence of data on such poverty indicators and the costs of collecting them for the whole population, it has become common in policy making to use proxy-means-testing (PMT) and other methods such as community-based targeting to target anti-poverty programs. ${ }^{11}$ A number of studies have assessed how well PMT does in targeting

\footnotetext{
${ }^{11}$ Using more easily observed correlates of consumption or income such as assets and household characteristics, PMT uses the predicted values from multivariate regressions for consumption or income.
} 
poor households (Brown et al. 2016; Alatas et al. 2012; Kidd and Wylde 2011), but there has been little attention to how well such methods identify disadvantaged individuals.

\section{A simple expository model}

An important point that has not received adequate attention in the literature on antipoverty policies is that heterogeneity in individual economic welfare at any given level of aggregate household welfare can severely restrict the scope for reaching vulnerable women and children using household poverty data. And this is the case even when there is a strong household income effect on individual welfare.

We elaborate this point in a simple expository model. To anticipate our empirical work, we shall identify individual welfare by nutritional status. The nutritional attainments of an individual are denoted $n$, while the wealth of the household to which the individual belongs is $w$. To keep notation simple, we take $n$ and $w$ to be normalized by appropriate cut-off points (stipulated nutritional thresholds or poverty lines) such that a person is undernourished if (and only if) $n<1$ and a household is wealth poor if $w<1$. These two random variables have a (continuous) joint density $f(n, w)$.

Following the discussion in the previous section, the relationship between the two variables depends on a number of factors, including (but not limited to) intra-household inequality, the local health environment (including water and sanitation), access to relevant health and nutritional knowledge, and child care. To keep the model simple, we collapse the heterogeneity into one composite factor denoted $\varepsilon$, which we can take to be scaled such that it is bounded below by zero and above by unity. For concreteness in interpreting the following results, we might suppose that $\varepsilon$ is the share of the household's total nutritional intake devoted to other household members. The expected value of individual nutritional status given $w$ and $\varepsilon$ is:

$$
E(n \mid w, \varepsilon)=n(w, \varepsilon)
$$

It is assumed that the function $n($.$) is strictly increasing in w$-the slope of this function with respect to $w$ is the aforementioned wealth effect on undernutrition —and that the function is strictly decreasing in $\varepsilon$ at given $w$. (Continuing the previous example, we can have the special case $n()=.(1-\varepsilon) \phi(w)$ where $\phi(w)$ is aggregate household nutrition when wealth is $w$.

Motivated by the existence of a wealth effect on nutritional attainments, it is understandable that a policy maker may be drawn to targeting wealth-poor households so as to reach nutritionally-deprived 
individuals. However, the common finding in the literature (reviewed in Section 2) that the expected value of nutritional status rises with wealth does not imply that household wealth provides a reliable indicator of individual outcomes for the purposes of policy. It makes more sense to focus instead on the conditional probability distribution $\operatorname{Pr}(w<1 \mid n<1)$, i.e., the probability of living in a wealth poor household given that one is undernourished. (For example, if an antipoverty policy made a transfer payment in a fixed amount to every poor household $(w<1)$ then the proportion that reached poor individuals will be $\operatorname{Pr}(w<1 \mid n<1)$.) By well-known properties of conditional probabilities: ${ }^{12}$

$$
\operatorname{Pr}(w<1 \mid n<1)=\frac{\operatorname{Pr}(n<1, w<1)}{\operatorname{Pr}(n<1)}
$$

The numerator is the joint probability of being both undernourished and living in a poor household, and the denominator is the overall rate of undernutrition. ${ }^{13}$ Notice that, in the special case in which $\operatorname{Pr}(w<1)<\operatorname{Pr}(n<1)$ and all of the wealth poor are undernourished $(\operatorname{Pr}(n<1 \mid w<1)=1)$, we have (on applying Bayes’ theorem):

$$
\operatorname{Pr}(w<1 \mid n<1)=\frac{\operatorname{Pr}(w<1)}{\operatorname{Pr}(n<1)}<1
$$

So the conditional probability is then bounded above by a number less than unity. Such cases will be noted when we come to discuss our empirical results.

We can now readily see how heterogeneity can confound a policy maker's ability to reach undernourished individuals using only household data. Let $w^{*}$ denote the minimum level of wealth that is needed to not be undernourished given $\varepsilon$, i.e., $n\left(w^{*}, \varepsilon\right)=1$. Plainly, $w^{*}$ is a strictly increasing function of $\varepsilon$, which we write as $w^{*}(\varepsilon) \cdot{ }^{14}$ Then we have:

$$
\operatorname{Pr}(w<1 \mid n<1)=\operatorname{Pr}\left[w<1 \mid w<w^{*}(\varepsilon)\right]
$$

\footnotetext{
${ }^{12}$ Alternatively, one might calculate $\operatorname{Pr}(n<1 \mid w<1)$. However, focusing on $\operatorname{Pr}(w<1 \mid n<1)$ seems to accord more directly with the relevant question for policy purposes. Of course the two conditional probabilities are linked by Bayes' theorem. Readers can back out $\operatorname{Pr}(n<1 \mid w<1)$ from our results below.

${ }^{13}$ More precisely $\operatorname{Pr}(n<1, w<1) \equiv \int_{0}^{1} \int_{0}^{1} f(n, w) d n d w$ and $\operatorname{Pr}(n<1) \equiv \int_{0}^{1} \int_{0}^{\infty} f(n, w) d w d n$.

${ }^{14}$ In the aforementioned example in which $\varepsilon$ is the nutrient share going to others such that $n=(1-\varepsilon) \phi(w)$ we have $w^{*}=\phi^{-1}\left[(1-\varepsilon)^{-1}\right]$.
} 
Now consider the lower and upper bounds of $\varepsilon$. We assume that the wealth-poverty line is set such that nutritional status is deemed to be adequate for someone at that line when $\varepsilon=0$. For example, when intra-household inequality is the source of heterogeneity, a fair division of food should allow all those living in households around the poverty line to be adequately nourished. Then $w^{*}(0) \leq 1$ and $\operatorname{Pr}\left(w<1 \mid w<w^{*}(0)\right)=1$. That is, targeting the wealth poor when there is no intra-household inequality assures that one reaches all those households with undernourished individuals. By contrast, given that $w^{*}$ is an increasing function of $\varepsilon$, when $\varepsilon$ approaches its maximum value, a high level of household wealth will be needed to assure that enough of the household's resources "trickle down” to avoid undernutrition in women and children. (This is clear if one considers again the example when $\varepsilon$ represents intra-household inequality.) Specifically, $w^{*}(1)=w^{\max }$ and $\operatorname{Pr}\left(w<1 \mid w<w^{\max }\right)=\operatorname{Pr}(w<1)$. As $\varepsilon$ approaches its upper limit, the probability of reaching undernourished individuals by targeting poor households is no higher than the overall poverty rate. By invoking continuity, it is clear that $\operatorname{Pr}(w<1 \mid n<1)$ must be a non-increasing function of $\varepsilon$ over $(0,1)$ and strictly decreasing for some subintervals. Thus we see that the value of $\varepsilon$ determines whether targeting poor households is effective in reaching poor individuals.

We will study how the conditional probability varies across countries with the overall poverty rate. Intuitively, the higher the household poverty rate the more likely it is that a policy that successfully targeted poor households will reach poor individuals. But how much better will it be? To answer this we assume that the empirical relationship can be written as:

$$
\operatorname{Pr}(w<1 \mid n<1)=\psi[\operatorname{Pr}(w<1)]
$$

where $\psi$ is a continuous function estimable by regression. If we consider a uniform transfer to the poorest $p \%$ of households then the function $\psi$ can be interpreted as the share of those transfers going to the poorest individuals, as assessed by their nutritional status. There are obvious boundary conditions to impose on the function $\psi$. When nobody is wealth poor none of the undernourished will be wealth poor, yet when everyone is wealth poor, this must of course also hold for the undernourished; in terms of equation (4) we expect that $\psi(0)=0$ and $\psi(1)=1$. So the empirical relationship must be increasing, although not necessarily monotonically. We can also expect that $\psi[\operatorname{Pr}(w<1)] \geq \operatorname{Pr}(w<1)$ (given a positive wealth effect on undernutrition). 
In our empirical implementation across 30 countries in SSA we will assume that $\psi$ is a quadratic function, which has an appealing interpretation. To see this not that, on imposing the boundary conditions, $\psi(0)=0$ and $\psi(1)=1$ and allowing for an error term, (4) can be written as:

$$
\operatorname{Pr}(w<1 \mid n<1)-\operatorname{Pr}(w<1)=-\beta \operatorname{Pr}(w<1)[1-\operatorname{Pr}(w<1)]+v
$$

Where $\beta>0$ is a parameter to be estimated using the estimates we obtain across countries. To help interpret $\beta$ it can be noted that its value is directly proportional to the concentration index:

$$
C=\int_{0}^{1} \psi(x) d x-0.5
$$

For a quadratic $\psi$ function (implying (5)), it is readily verified that $\beta=6 C$. Thus $\beta$ can be interpreted as an overall measure of how much more effective it is to target poor households (aiming to reach poor individuals) when the overall household poverty rate is higher. When $\beta=0$, the conditional probability of an undernourished person living in a wealth-poor household is no different (in expectation) to the overall wealth-poverty rate as one varies the latter from 0 to 1 . This will be the case if there is no wealth effect on undernutrition. At the other extreme, when $\beta=6(C=1)$, one finds that all undernourished individuals are found in wealth poor households, and it is evident that (given our quadratic parameterization) this holds at each and every point.

It is less clear how the conditional probability in (2) varies with the overall rate of undernutrition, $\operatorname{Pr}(n<1)$. In countries in which the rate of undernutrition is higher do we find that a higher proportion of the undernourished also live in wealth-poor households? The value of $\operatorname{Pr}(w<1 \mid n<1)$ is undefined at the lower bound of undernutrition, $\operatorname{Pr}(n<1)=0$. Comparing strictly positive values, a higher $\operatorname{Pr}(n<1)$ can come with a change in the numerator of (2), so that it cannot be presumed that the conditional probability will fall. To see why, suppose that there is a change in the joint distribution $f(n, w)$, such that $\operatorname{Pr}(n<1)$ increases. Furthermore, suppose that the joint probability increases for all points with $n<1$ and $w<1$, while the opposite happens at all other points in the $(n, w)$ space. In this case, it is clear that the joint conditional probability must also increase along with the marginal, with a theoretically ambiguous implication for the conditional probability. (A similar argument can be made with respect to how $\operatorname{Pr}(w<1 \mid n<1)$ varies with $\operatorname{Pr}(w<1)$.) 
The model above formalizes the intuition that heterogeneity, such as due to intra-household inequality or the local health environment, diminishes the scope for reaching poor individuals by targeting poor households. It also shows that there is wide variation in how effective targeting poor households will be for reaching undernourished individuals, and that higher rates of undernutrition have an ambiguous effect on the conditional probabilities. But how much does this matter empirically? Is the wealth effect on individual nutritional status strong enough to allow satisfactory targeting of vulnerable women and children? The rest of this paper addresses these questions, also using some of the measurement concepts above.

\section{Data}

Our data are drawn from the Demographic and Health Surveys (DHS) and the Living Standards Measurement Study (LSMS). We use the most recent DHSs available at the time of writing and recent LSMSs that collected nutrition data. ${ }^{15}$ The Addendum to this paper gives details on the sample sizes and years for all the DHS and LSMS surveys used in this study.

Individual nutritional outcomes: We study the nutritional outcomes of women and children. For women, the two variables we employ are the body mass index (BMI) (also known as the Quetelet index, defined as a woman's weight (in kilograms) divided by her height (in meters) squared) and an indicator for being underweight, which is set equal to one if a woman's BMI is lower than 18.5 and zero otherwise. The DHSs exclude values of BMI that are smaller than 12 and greater than 60 on the grounds that these are almost certainly measurement errors. We do the same for the consumption surveys. BMI is computed by the DHSs for samples of women aged 15 through 49. For the LSMSs we restrict women to the same age range. We exclude all women who report being pregnant at the survey date. ${ }^{16,17}$ On average, pregnant women represent approximately 10 percent of all women aged between 15 and 49. The Addendum gives the pregnancy incidence for each country in the DHS dataset.

\footnotetext{
${ }^{15}$ Several countries with DHSs had to be excluded due to older survey dates that did not contain many of the key variables needed, namely the Central African Republic, Chad, Comoros, Madagascar, Sao Tome and Principe, and South Africa. ${ }^{16}$ Unfortunately, we are unable to exclude pregnant women for Tanzania's consumption survey as it did not ask women whether they were pregnant.

${ }^{17}$ We also dropped observations with missing values for any variables used in the paper, such that sample sizes are consistently the same and comparable throughout the paper. However, we tested the effect of relaxing this constraint and found that it makes negligible difference to the results.
} 
For children, we use the z-scores for height-for-age (stunting) and weight-for-height (wasting). ${ }^{18}$ These anthropometric data are measured for all children aged under 5 in the DHSs and LSMSs. We then create our measure for stunting (low height-for-age) and wasting (low weight-for-height). A child is deemed to be stunted if his height-for-age z-score is two standard deviations below the median of the reference group; wasting is defined similarly using weight-for-height. Stunting and wasting, while both considered indicators of undernutrition, have different causes and effects. Stunting is an indicator of persistent, longer-term, chronic undernutrition from which it is much harder for a child to recover. Compared to wasting, it is known that stunting has adverse longer term consequences for child development. ${ }^{19}$ Wasting tends to be more responsive to short-term (possibly seasonal) food deprivations or illnesses.

Tables 1 and 2 give the summary statistics for the nutritional outcomes for women and children using the DHSs and LSMSs. ${ }^{20}$ Focusing on the larger sample of countries available in the DHSs and taking population-weighted averages, we find that $11 \%$ of adult women are underweight, while $32 \%$ of children are stunted and 9\% are wasted (similar numbers are found for children in the LSMSs). Boys are found to have a generally higher incidence of both stunting and wasting relative to girls although not all the differences at the country level are statistically significant. ${ }^{21}$ Across countries, a higher incidence of underweight women is associated with a higher incidence of wasted children $(r=0.40$, significant at the $5 \%$ level $^{22}$ ). The correlation between women's and children's nutritional status is weaker for stunting $(r=0.14) .{ }^{23}$ This is what we would expect if a woman being underweight and her children being wasted are caused by similar short-term shocks, while stunting is a more long-term condition.

For a subset of countries, the DHS additionally collected data on adult male anthropometrics which provide an insight into the extent of intra-household inequality. Table 3 provides summary statistics on the incidence of undernutrition for women and children stratified according to whether the male head of household is underweight or not. We see that the incidence of undernutrition among

\footnotetext{
18 These variables are already constructed in the DHSs. For the consumption surveys we use the Stata command zscore06 to convert height and weight values into a standardized value. Z-scores are calculated using the WHO 2006 standard.

${ }^{19}$ See, for example, Walker et al. (2007) and Hoddinott et al. (2008).

${ }^{20}$ There are some discrepancies in the means between the two datasets, much of which is likely to do with the timing of the surveys, although differences in sample selection and measurement may also be contributing.

${ }^{21}$ This result for the African context was first discussed in Svedberg (1990). Since then others report similar findings for SubSaharan Africa (for example, WHO 2016 (Figure 8.7); Wamani et al. 2007).

${ }^{22}$ For prob. $=0.05$, the critical value of the correlation coefficient is 0.306 .

${ }^{23}$ This weak correlation between wasting and stunting is not surprising (Victora 1992). Although there is some evidence that wasting in early childhood can cause subsequent stunting (Richard et al. 2012), the fact that stunting is a longer-term condition while wasting tends to be more transient points to different causative factors.
} 
women and children is lower when the male head is adequately nourished. However, substantial inequality in nutritional status is also evident, and the gender inequality goes in both directions. The majority of women in households where the male head is underweight are not undernourished, and there is a high incidence of undernutrition among women and children in households where the male head is not underweight. Table 3 also gives (in parentheses) the proportions of undernourished women and children found in the two groups of households, identified by whether the male head is underweight or not. (Note that the proportions sum to unity horizontally.) We see that the bulk of underweight women (74\%) are found in households where the male head is not underweight and similarly for stunted (80\%) and wasted (53\%) children.

Wealth and other covariates: When we say that a household is "wealth-poor" we are referring to the DHS wealth index within a given country. The wealth index is a composite of variables related to a household's assets (including consumer durables) and amenities, including materials used for housing construction and its access to water and sanitation. These variables are then aggregated by the DHS into an index using factor-analytic methods, with the wealth index being identified as the first principal component of the data. The DHS wealth index comes as a z-score, i.e., standardized with mean zero and standard deviation of unity. So the index is country specific - not intended to be comparable across countries. We take this index as given.

We focus on the poorest $20 \%$ and $40 \%$ of households based on the wealth index. These are arbitrary choices, although the $40 \%$ figure does coincide fairly closely with the overall poverty rate found for SSA using the World Bank's international line (Addendum). ${ }^{24}$ The $20 \%$ figure allows us to focus on the lower part of the wealth distribution. We also provide key results for the full range of the distribution.

It should not be forgotten that the DHS wealth index is a proxy, not a direct measure of wealth. The index focuses on durable and productive asset wealth rather than labor or education wealth, arguably the main assets of many among the poor. When compared to the results of a consumption survey, the DHS index will undoubtedly count as poor some who are not (often called "inclusion errors”) and count as non-poor some of those who are in fact poor (“exclusion errors”). Though in practice, policy makers almost never have access to accurate measures of wealth or consumption, we also conduct the analysis using household consumption per capita for the sub-set of countries for which

\footnotetext{
${ }^{24}$ Using the World Bank's international line of $\$ 1.90$ a day at 2011 purchasing power parity, 43\% of the population of subSaharan Africa are found to be poor in 2013 (based on PovcalNet).
} 
this is feasible. Surveys that contain detailed household consumption data as well as anthropometrics for women and children are not common, but some do exist including within the LSMSs (specifically the LSMS Integrated Surveys on Agriculture) as listed in the Addendum. ${ }^{25}$ The consumption variable is spatially deflated and expressed in per capita terms.

In an attempt to test whether controlling for additional information, including education and labor assets, enhances predictive power, we draw on household and individual covariates from both surveys. Variables based on the consumption surveys are constructed to be as similar as possible to those available in the DHS data.

The Addendum provides summary statistics for the wealth index and other key variables that are typically included in the index or are standard in proxy-means-testing for each country. Descriptive statistics for the variables from the consumption surveys are also shown in the Addendum. Overall, means match reasonably well between the two datasets, though with some differences among the asset variables.

\section{Individual outcomes and household wealth}

Wealth effects on nutritional status: Figure 1 plots the incidence of the three anthropometric indices against percentiles of the household wealth index. Given that younger women typically have a lower BMI, we plot incidence for all women 15 to 49 years of age, as well as for women 20 to 49 years of age.. The wealth effect—whereby nutritional status improves with a higher DHS wealth index-is generally evident. However, aside from child stunting, the wealth effect is clearly weak in most countries. The incidence of being underweight is slightly higher for younger women, although the relationship with household wealth is very similar. Child wasting in some countries shows little or no sign of the wealth effect (notably Gabon, Gambia, Senegal, Sierra Leone and Swaziland). Figure 2 gives the corresponding graphs using household consumption per capita. Similar comments apply.

The overall strength of the household wealth effect for each country can be assessed by regressing the standardized values for nutritional status (that is, the z-score for women's BMI and height-for-age and weight-for-height z-scores for children) on the wealth index, which (as noted) is also a z-score. The regression coefficient gives the number of standard deviations of the nutritional indicator attributed to a one standard deviation increase in wealth. Table 4 gives results using the DHS, and the analogous results using standardized consumption z-scores from the LSMS. The estimated wealth

\footnotetext{
${ }^{25}$ Only the consumption survey from Ghana is not one of the Integrated Surveys on Agriculture within the LSMS.
} 
effects are statistically significant in almost all cases (the exceptions are for child wasting in a few countries). For women’s BMI the mean regression coefficient is 0.26 , while it is 0.29 for the height-forage z-score and only 0.09 for weight-for-height. (The Addendum gives the coefficients separately for boys and girls; the results are similar with no clear pattern in evidence.) For the countries where the wealth effect on child stunting is highest (Burundi, Cameroon and Nigeria), a one standard deviation increase in wealth is associated with a 0.5 standard deviation increase in the incidence of child stunting. For about half the countries, the wealth effect on stunting is less than 0.3 standard deviations. The overall incidence of undernutrition makes little different to the results, i.e. countries with low incidence of undernutrition do not have stronger or weaker wealth effects relative to countries with a high incidence of undernutrition.

However, these results cannot tell us much about the efficacy of household wealth as a tool to reach undernourished individuals. Low wealth effects such as evident in Table 4 need not imply that the incidence of undernutrition is unresponsive to income or wealth differences (as demonstrated in Ravallion, 1990). Moreover, as shown in Section 3, even if household wealth and individual nutritional status are correlated it does not follow that a large proportion of undernourished individuals will be found in the lower ends of the wealth distribution.

Conditional and joint probabilities: Figure 3 gives the concentration curves, i.e., the cumulative share of undernourished individuals by cumulative household wealth percentile ranked from the poorest up. The greater the degree of concavity (intuitively meaning that the concentration curve is further above the 45-degree line), the more undernourished individuals tend to be concentrated in the poorer strata of household wealth. Similarly, Figure 4 displays the concentration curves using household consumption per person as the ranking variable.

We see in Figure 3 that there is marked concavity for some countries, notably Cameroon (for all three indicators), Congo, Gabon and Ghana (for stunting), Gabon, Kenya, Uganda, Zambia and Zimbabwe (for underweight women). However, in most cases the curves tend to be fairly close to the diagonal line. The curve for underweight women tends to be above that for children in about half the countries, though otherwise there is little sign of a clear ranking of the three indicators.

For the rest of this discussion we focus on the points on the concentration curves corresponding to the poorest $20 \%$ and $40 \%$ of the household wealth index. Table 5 presents the proportion of undernourished women and children who falls into the bottom 20 and 40 percent of the household 
wealth distribution. ${ }^{26}$ Given the wealth effect on nutritional status, the values for underweight women and stunted children are generally bounded below by $\operatorname{Pr}(w<1)$ (either 0.2 or 0.4 ). The only exceptions are for underweight women in Cote D’Ivoire, Gambia (for poorest 20\%), and Gabon (for poorest 40\%), and child wasting in Gambia, Senegal, Sierra Leone and Swaziland, where the wealth effect is not evident (Figure 1).

There are a number of cases in which the rate of undernutrition exceeds the wealth poverty rate i.e. $\operatorname{Pr}(w<1)<\operatorname{Pr}(n<1)$. Recall from Section 3 that in such cases the conditional probability is bounded above by the ratio of the poverty rate to the rate of undernutrition. Indeed, this is true in most cases for child stunting using the $20 \%$ cut off (though it is never the case for wasting) and in two cases for women, namely Ethiopia and Senegal (Table 1). It follows then that the conditional probabilities will be less than unity in these instances.

However, what is striking about the results in Table 5 is how close the conditional probabilities are to $\operatorname{Pr}(w<1)$. For 25 of the 30 countries less than $30 \%$ of underweight women are found in the poorest $20 \%$ of households. This is true for 19 and 22 countries with regard to stunted and wasted children (respectively). On average, roughly three-quarters of underweight women and undernourished children are not found in the poorest $20 \%$ of households when judged by household wealth. And about half of underweight women and undernourished children are not found in the poorest $40 \%$ of households.

We also did a breakdown of the conditional probabilities for stunting and wasting by gender. Stunted and wasted girls are slightly more likely to be found in the bottom $20 \%$ and $40 \%$ of household wealth than boys overall. However, this varies across countries. Boys have a slightly higher joint probability on average; details can be found in the Addendum. However, the gender differences are generally small.

The countries with a higher percentage of undernourished women in the poorest strata of households tend to also have a higher proportion of wasted children in that group; the correlation coefficients are 0.62 and 0.64 for the poorest $20 \%$ and $40 \%$ respectively. This is also true for stunted children although the correlations are somewhat weaker; the corresponding correlation coefficients are

\footnotetext{
${ }^{26}$ We also calculated the conditional probabilities for severely stunted children, where severe stunting is defined as three or more standard deviations below the median height-for-age and weight-for-height z-scores respectively. Compared to Table 5, we find that severely stunted children are more likely to be found in the poorest $20 \%$ and $40 \%$ of households; while on average, $29 \%$ of stunted children are in the poorest wealth quintile this rises to $33 \%$ for severely stunted children. Full results can be found in the Addendum.
} 
0.33 and 0.43 . There are only three countries (Cameroon, Ghana and Kenya) where more than $30 \%$ of nutritionally deprived individuals are found in the poorest $20 \%$ for all three nutritional indicators.

Table 6 provides the same statistics using the consumption indicator, with very similar results. Overall, $70 \%$ of undernourished women are not found in the poorest $20 \%$ of households based on consumption per person, while half of them are not found in the poorest $40 \%$. For children, we similarly find that about $70 \%$ of stunted and wasted children are not found in the poorest $20 \%$. A little less than half of stunted and wasted children are not found in the poorest $40 \%$. Table 6 also lists the proportion of undernourished women and children found in households deemed poor using the \$1.90 per day poverty rates. The pattern is similar to our findings using the wealth rankings, with conditional probabilities only slightly higher than the national poverty rates in most cases. Even in countries with very high poverty rates such as Burkina Faso and Malawi, the proportion of undernourished children found in poor households is not much different to the poverty rate itself.

On combining Tables 1 and 5, we can use equation (2) to infer the joint probabilities of being both undernourished and wealth-poor, $\operatorname{Pr}(n<1, w<1)$. The empirical values for the DHS data are given in Table 7. For underweight women and the poorest $20 \%$, the joint probability is under 0.04 for 26 countries. The mean joint probability of a woman being underweight and living in the poorest $20 \%$ of households is only 0.03 , rising to 0.05 for the poorest $40 \%$. For child wasting, the probabilities are even lower than for underweight women, at under 0.02 for two thirds of all countries. The joint probabilities are higher for stunting, with a mean of 0.09 and 0.18 for the poorest $20 \%$ and $40 \%$, respectively.

As expected, the joint probabilities tend to be positively correlated with the marginals; the bottom row of Table 7 gives the correlation coefficients. The table also gives the OLS elasticities across countries (regression coefficients of the log joint probability on the log marginal probabilities). The elasticities are all less than unity, implying that a higher rate of undernutrition should reduce the conditional probability. On balance, we do find that countries with a higher overall incidence of undernutrition tend to have a higher share of these disadvantageous outcomes among the "non-poor" based on wealth. Figures 5, 6 and 7 plot the values from Tables 2 and 8 for the incidence of underweight women, stunting and wasting respectively, highlighting the negative relationship between the joint and marginal probabilities.

These results suggest that when relatively few women or children are undernourished in a country one tends to find them more concentrated in relatively poorer households. Conversely, when there are many undernourished women and children one tends to find them more widely spread across 
the household wealth distribution. From a policy perspective, these results suggest that targeting relatively poor households will tend to work less well in reaching vulnerable women and children in countries where the overall problem of undernutrition is greater. ${ }^{27}$

\section{Explanations}

We comment on a number of possible explanations for our findings.

Demographics of the poverty profile: As noted in Section 2, it might be conjectured that a demographic imbalance between wealth fractiles is playing a role in our findings, given that poorer households are often found to include more children. To account for the possibility that children (and possibly women) are distributed unevenly across the household wealth distribution, we recalculate wealth percentiles by balancing the demographic composition separately for women and children. In other words, we rank all children (and similarly women) according to their household wealth and create wealth percentiles such that $\mathrm{x} \%$ of children fall into the bottom $\mathrm{x} \%$ of the wealth distribution. We call this the demographically-balanced wealth distribution.

We found that the conditional probabilities using the demographically-balanced wealth fractiles are very similar to those seen in Table 5 (full details are in the Addendum). On average, a slightly higher proportion of undernourished women are located in the poorest 20 and 40 percent of the individual wealth distribution relative to the household wealth distribution. The opposite is found for stunted and wasted children (although this varies across countries), suggesting that poorer households do contain a higher proportion of stunted and wasted children, though the difference is not large. The Addendum gives the joint probabilities, with similar findings. The Addendum also provides both conditional and joint probabilities for the consumption data. We conclude that demographic imbalance is not an important factor in explaining our results.

Selective child mortality: About $10 \%$ of children born in Sub-Saharan Africa die before they reach five years of age. It is also known that mortality rates tend to be higher for poorer families. ${ }^{28}$ As noted in Section 2, there have been some studies of the effects of such selective mortality (also called “survivor bias”) on various measures although the effects documented have tended to be small (Boerma

\footnotetext{
27 This is also evident in the data for stunting in Africa assembled by Bredenkamp et al. (2014) (see the Africa data points in their Figure 1), although across all developing countries Bredenkamp et al. find that inequalities in stunting are greater in countries where stunting is more prevalent. Evidently Africa is different in this respect, though the reason is unclear.

${ }^{28}$ See, for example, UNICEF (2011, Figure 7). Ravallion (2016, Chapter 7) reviews past studies on the socio-economic differentials in child mortality.
} 
et al. 1992; Bozzoli et al. 2007; Alderman et al. 2012). How much are our results on the conditional probabilities in Table 5 likely to have been affected by selective child mortality?

We do not of course know what the nutritional status of the children who died would have been had they lived. Child mortality is clearly more likely when children are undernourished, whether living in a poor household or not. We assume that all those who died (whether living in poor households or not) were undernourished. This is not likely to strictly hold, but it seems the most reasonable assumption to make in this context. Naturally, child deaths among the undernourished living in non-poor households will counteract to some extent the effect of selective mortality on the probability of living in a poor household given that one is undernourished.

Under this assumption one can readily derive the following formula for the counterfactual conditional probability without child mortality:

$$
\operatorname{Pr}^{*}(w<1 \mid n<1)=\frac{\operatorname{Pr}(w<1 \mid n<1) \operatorname{Pr}(n<1)+M(w<1) \operatorname{Pr}(w<1)}{\operatorname{Pr}(n<1)+M}
$$

Here $M=C M R /(1-C M R)$ is the ratio of recorded child deaths to the number of live children, where $C M R$ is the overall child mortality rate (as a proportion of live births), while $M(w<1)$ is the corresponding odds ratio for poor households $;^{29}$ selective mortality here means that $M(w<1)>M$. Also, $\operatorname{Pr}(w<1)$ is defined as the poverty rate for children (the proportion of children under five living in poor households). From equation (7) we can see that $\operatorname{Pr}^{*}(w<1 n<1)>\operatorname{Pr}(w<1 \mid n<1)$ if and only if $M(w<1) / M>\operatorname{Pr}^{*}(w<1 \mid n<1) /(\operatorname{Pr}(w<1)$. Thus it is an empirical question as to whether selective mortality increases the conditional probability under our assumptions.

Averaged over all 30 countries we find $M=0.140$ while for the poorest $20 \%$ we obtain $M(w<1)$ $=0.157$. And we find that $\operatorname{Pr}(w<1)=0.235$. On using our data to evaluate the above formula we find that the counterfactual conditional probability for child stunting is 0.28 , as compared to 0.29 in Table 5 . For the poorest $40 \%$, the estimated counterfactual conditional probability is 0.54 , as compared to 0.55 (Table 5). $(\operatorname{Pr}(w<1)=0.459$.) For child wasting, the mean counterfactual probabilities of 0.27 and 0.51 are essentially no different to that in Table 5 for the poorest $20 \%$ and $40 \%$ respectively. Thus, under our assumptions, selective mortality is not attenuating the conditional probability of interest.

\footnotetext{
${ }^{29}$ Note that the odds ratio appears here because child mortality rates are usually expressed as a proportion of live births.
} 
Measurement error in nutritional outcomes: Another potential explanation for the above results is measurement error in the nutritional outcomes. This could be particularly true for very young children, for which accurate anthropometric measurement can be difficult (Ulijaszek and Kerr 1999; Larson et al. 2017; Agarwal et al. 2017). We re-estimate the conditional probabilities for stunting and wasting for children 18 months and older only. We find very similar results to Table 8; on average, only $29 \%$ of stunted children and 28\% of wasted children 18 months and over are found in the poorest $20 \%$ of households. (Full results can be found in the Addendum.)

We further consider the relationship between nutritional outcomes for mothers and their children. If measurement error in outcomes is confounding the results, we might expect the relationship to be quite weak. We first look at the difference in means for both height-for-age and weight-for-height zscores for children with underweight mothers and find that children whose mothers are underweight have significantly lower height-for-age and weight-for-height z-scores across almost all countries (the Addendum contains the full results). Correlation coefficients between mothers’ BMI and child heightfor-age and weight-for-height z-scores are positive and significant for all countries except Lesotho (see the Addendum). While measurement error may be a factor, it is unlikely to fully explain our results.

Intra-household inequality in nutritional status: Table 8 examines the variation in nutritional outcomes within the household. Using the DHSs for which nutritional outcomes are available for all household members, we construct a binary indicator variable set equal to one if an adult is considered underweight, or if a child is either stunted and/or wasted, and zero otherwise. Using the mean and variance from the Bernoulli distribution, we can look at average variation in undernutrition within the household across countries for which we have nutritional data for all household members. For example, the entry "0.338" under "Mean” for Ethiopia indicates that 34\% of individuals in the sampled households were deemed to be nutritionally deficient (either in terms of BMI for adults or one or both zscores for children); when stratified by whether the male head is underweight or not, the corresponding percentages are $65 \%$ and $19 \%$.

The higher the mean rate of undernutrition, the higher the average variance within households. However, when we break down variation within households by gender of the household head, we find that even though the average rate of undernutrition is higher for households with underweight female heads relative to underweight male heads, the average variation within the household in terms of nutritional outcomes is much lower. A similar pattern emerges when we consider male and female heads 
who are not underweight. This suggests that there is less intra-household inequality in terms of nutritional outcomes in households headed by women relative to those with male heads.

How much does intra-household inequality in nutritional status contribute to the seemingly low conditional probabilities that we have found (such as in Table 5)? A straightforward way to assess this is to re-calculate the conditional probabilities using artificial distributions in which we replace the measured BMI of each adult by the household mean BMI, and similarly for children's z-scores. That is, every adult and child within the household has the same nutritional status. Table 9 gives the results. The column "actual” refers to the calculated conditional probability from the original data. The numbers under "regular cutoff" are the corresponding probabilities when we re-assign each adult the household mean BMI and similarly for children. Given that the distribution functions are not linear, equalizing the nutritional status within households does not assure that the overall rate of undernutrition is unchanged, so the numbers in the "regular cutoff" column may be affected by the change in the mean undernutrition rate. To check this possibility, we also give estimates under "new cutoff” in which we adjust the nutritional thresholds to balance the overall rate of undernutrition. ${ }^{30}$ In almost all cases we find that the conditional probabilities are higher when we artificially eliminate intra-household inequality. However, the effect is modest. While intra-household inequality is clearly lowering the conditional probabilities, it is clear that other factors are in play.

Common health risks: It is known that health shocks often impede nutritional absorption. While it is likely that higher household wealth can help parents protect their children from health risks, there are clear limits, leaving locally covariate health risks facing children in non-poor families. The DHS provide some useful clues to the extent of these common health risks. For children under 5, Figure 8 plots the incidence of reported diarrhea in the past two weeks, the incidence of blood in the stool (when diarrhea is reported), and the incidence of fever in the last two weeks. While there are signs of a wealth effect in most cases, it is clearly not strong. It is evident that health risks are spread quite widely across the distribution of households in all countries studied, which is likely to be a contributing factor in our results on the conditional probabilities.

Other sources of heterogeneity: Introducing other household-level factors can be expected to enhance power for predicting individual outcomes. Separating out the components of the DHS wealth index can also help address possible concerns with the weights used in constructing the index; for

\footnotetext{
${ }^{30}$ Recall that for two of the countries in Table 15 (Ethiopia and Senegal) the undernutrition rate for women exceeds 20\%. For these countries, the conditional probability cannot exceed 0.75 and 0.90 . Even so, it remains clear that only a small share of the gap between the estimated conditional probability and its maximum value can be attributed to intra-household inequality.
} 
example, the index may not adequately adjust for economies of scale in consumption. Adding basic individual-level variables such as age, education and marital status for women may also enhance targeting capability. ${ }^{31}$ For example, mother's education is likely to be an important factor especially through knowledge about nutrition and health care. To test these conjectures we use an augmented regression to include such household- (and individual-) level variables. The regressions can be expected to perform similarly to the widely-used PMT method based on the predicted values of regressions calibrated to survey data (Brown et al. 2016).

The first model we consider regresses nutritional outcomes on the household wealth index and other household-level variables:

$$
y_{i j m}=\alpha_{m}+\beta_{m} w_{j m}+\gamma_{m} x_{j m}+\varepsilon_{i j m}
$$

where $y_{i j m}$ is the anthropometric index for individual $i$ in household $j$ in country $m$ and $w_{j m}$ is the household wealth index. The vector $x_{j m}$ includes the separate components of the wealth index (essentially to allow a re-weighting of the index), as well as other household-level variables such as size and composition, and characteristics of the head. Dummies for survey month and region of residence are also entered as controls. Model 2 adds the observable individual-level variables, $z_{i j m}$ :

$$
y_{i j m}=\alpha_{m}+\beta_{m} w_{j m}+\gamma_{m} x_{j m}+\delta_{m} z_{i j m}+\varepsilon_{i j m}
$$

For the incidence of underweight women, the individual-level attributes include the woman's age (BMI tends to increase as women age), education and marital status. For children, age, gender, and characteristics of the child's mother are included. To avoid ad hoc functional form assumptions, age and education variables as well as household size are broken into categories each of which is entered as a dummy variable. OLS is used to estimate each model, with standard errors clustered at the PSU. (The Addendum gives the actual regressions.)

Tables 10 and 11 present the results for Models 1 and 2 for underweight women and undernourished children respectively. The tables give the proportion of undernourished individuals who fall into the poorest $20 \%$ and $40 \%$ of the distribution of the predicted values based on wealth and (unlike prior tables) the additional covariates. We find that, on average, 32\% of underweight women are found in the poorest 20\% based on the predicted values from Model 1 (Table 10), as compared to 25\% using only the household wealth index (Table 5). Focusing instead on the poorest 40\%, the proportion rises to 56\% using Model 1, as compared to 48\% using wealth alone. Adding the individual variables (Model 2)

\footnotetext{
${ }^{31}$ Recent research has argued that widows and remarried women often fare poorly when compared to married once women (Anderson and Ray 2015; Djuikom and van de Walle 2017).
} 
we now find that (on average) $37 \%$ of underweight women are found in the poorest $20 \%$ in terms of the predicted values, rising to $61 \%$ for the poorest $40 \%$. Similar improvements are evident for both stunting and wasting in children (comparing Tables 11 and 5).

Among all the changes we have considered, these augmented regressions do the most to raise the conditional probabilities. This is possibly not surprising given the large amount of extra data used and the fact that the predicted values are calibrated to explaining individual attainments. That appears to be rare in practice; for example, popular PMT methods are calibrated to explain household consumption rather than individual nutritional status (Brown et al., 2016). Nor is it surprising that the probabilities generally reach their highest values when one includes individualized data; household data alone cannot be expected to do as well. However, based on Tables 10 and 11 it cannot reasonably be said that even these predicted values based on augmented regressions calibrated to nutritional status do a good job at identifying undernourished individuals within households.

\section{Conclusions}

There are multiple constraints on effective policy interventions in practice. Focusing on a key but neglected informational constraint, we have asked whether household poverty might provide a reliable guide for policy efforts trying to reach deprived individuals, as indicated by anthropometric measures of undernutrition, recognizing that poverty is an individual characteristic. We do not claim that information is the only constraint. Even if undernourished women and children are mainly found in wealth- or consumption-poor households, other factors such as the local health environment can play an important role in determining policy effectiveness.

Individual welfare clearly depends on more than nutritional status, and we cannot rule out the possibility that household-level data are more revealing for other non-nutrition dimensions. That said, undernutrition is an undeniably important dimension of individual poverty and it has long played a central role in the measurement of poverty using household data. This dimension of welfare is also emphasized by policy makers concerned with reducing both current and longer-term poverty. The mounting evidence on the longer-term costs of stunting in young children adds force to that emphasis.

A great deal has been learnt about the socioeconomic differentials in individual health and nutrition from micro data, typically using cross-tabulations or regressions. This knowledge is valuable. However, there is a risk that the differentials in mean attainments often found between rich and poor households lead policy makers to be overly optimistic about the scope for reaching vulnerable 
individuals using household-level data. Standard poverty data make ad hoc assumptions about equality within households. Just how adequate household-level data are for the policy purpose of reaching vulnerable women and children has been unclear.

To help improve our knowledge about this informational constraint on policy, the paper has provided a comprehensive study for 30 countries in sub-Saharan Africa. We find a reasonably robust household-wealth effect on individual undernutrition indicators for women and children. Nonetheless, on aggregating across the 30 countries studied here, about three-quarters of underweight women and undernourished children are not found in the poorest $20 \%$ of households when judged by the household wealth index in the Demographic and Health Surveys. A similar pattern is found in the available household surveys that allow a comparison of individual nutritional measures with an estimate of the household's consumption per person, which is clearly the most widely used welfare metric in measuring poverty in developing countries. Adding other household variables-interpreted as either a re-weighting of the DHS wealth index or as supplementary variables_-improves the performance of household data in this respect, but we still find that a large share of undernourished individuals are not among those predicted to be undernourished based on household variables. It is clear from this study that to have any hope of reaching undernourished women and children, policy interventions in this setting will either require much more individualized intra-household information or they will need to be nearly-universal in coverage.

This dispersion of undernourished individuals across the distributions of household wealth and consumption entails that countries with a higher overall incidence of undernutrition tend to be countries where a larger share of the undernourished are found in non-poor families. This suggests that the need for broad coverage in social policies (rather than policies finely targeted to poor households) is especially great in countries with a high incidence of undernutrition. Rather than folding nutrition schemes into household-targeted antipoverty programs in such countries, emphasis should be given to nutritional interventions with near universal coverage, such as comprehensive school feeding (with explicit nutrition supplementation), maternal health care and universal sanitation services.

In addition to documenting the limitations of relying on household poverty data to reach nutritionally deprived individuals, we have thrown some light on why those limitations are so severe. For the subset of countries for which we also know adult male BMI, we have shown that the extent of intra-household inequality entails that the bulk of underweight women and undernourished children are found in households where the male head appears to be adequately nourished. The data also reveal less 
intra-household inequality in nutritional outcomes for households headed by women relative to those headed by men irrespective of whether the head is undernourished or not. However, simulations to quantify the contribution of intra-household inequality to lowering the conditional probabilities suggest that other factors are also playing an important role. We find evidence consistent with the view that covariate risks found in the local health environment help explain why undernutrition in children is spread so widely across the distribution of household wealth. 


\section{References}

Agarwal, Neha, Anaka Aiyer, Arpita Bhattacharjee, Joseph Cummins, Christian Gunadi, Deepak Singhania, Matthew Taylor and Evan Wigton-Jones. 2017. "Month of Birth and Child Height in 40 Countries,” mimeo, Department of Economics, University of California, Riverside.

Alatas, Vivi, Abhijit Banerjee, Rema Hanna, Benjamin Olken and Julia Tobias. 2012. “Targeting the Poor: Evidence from a Field Experiment in Indonesia,” American Economic Review 102(4): 1206-1240.

Alderman, Harold. 2015. “Leveraging Social Protection Programs for Improved Nutrition: Summary of Evidence Prepared for the Global Forum on Nutrition-Sensitive Social Protection Programs, 2015,” Available at SSRN 2831575 (2015).

Alderman, Harold, Michael Lokshin, and Sergiy Radyakin. 2011. "Tall Claims: Mortality Selection and the Height of Children in India," Economics \& Human Biology 9(4): 393-406.

Anderson, Siwan, and Debraj Ray. 2010. “Missing Women: Age and Disease,” Review of Economic Studies 77(4): 1262-1300. and . 2015. “Missing Unmarried Women,” NBER Working Paper 21511.

Baland, Jean-Marie, and Roberta Ziparo. 2017. “The (In)-efficiency of Intra-household Bargaining in Poor Countries,” mimeo, University of Namur.

Behrman, Jere, and Anil Deolalikar. 1987. "Will Developing Country Nutrition Improve with Income? A Case Study for Rural South India,” Journal of Political Economy 95: 108-138.

Bhalotra, Sonia, and Samantha B. Rawlings. 2011. “Intergenerational Persistence in Health in Developing Countries: The Penalty of Gender Inequality?” Journal of Public Economics 95(3): 286-299.

Bhalotra, Sonia, and Samantha B. Rawlings. 2013. "Gradients of the Intergenerational Transmission of Health in Developing Countries.” Review of Economics and Statistics 95(2): 660-672.

Bhutta Zulfiqar, Jai Das, Arjumand Rizvi, Michelle Gaffey, Neff Walker, Susan Horton, Patrick Webb, Anna Lartey, and Robert Black. 2013. "Evidence-Based Interventions for Improvement of Maternal and Child Nutrition: What Can be Done and at What Cost?” Lancet 382(9890): 452-77. Bicego, George, Shea Rutstein, and Kiersten Johnson. 2003. “Dimensions of the Emerging Orphan Crisis in Sub-Saharan Africa,” Social Science and Medicine 56(6): 1235-1247. 
Bidani, Benu and Martin Ravallion. 1997. “Decomposing Social Indicators Using Distributional Data,” Journal of Econometrics 77(1): 125-140.

Boerma, Ties, Elisabeth Sommerfelt, and George Bicego. 1992. “Child Anthropometry in Cross-Sectional Surveys in Developing Countries: An Assessment of the Survivor Bias,” American Journal of Epidemiology 135(4): 438-49.

Bozzoli, Carlos, Angus Deaton and Climent Quintanta-Domeque. 2007. “Adult Height and Childhood Disease,” Demography 46(4): 647-69.

Bredenkamp, Caryn, Leander R Buisman and Ellen Van de Poel. 2014. "Persistent Inequalities in Child Undernutrition: Evidence from 80 Countries, from 1990 to Today,” International Journal of Epidemiology 43(4): 1328-1335

Brown, Caitlin, Martin Ravallion and Dominique van de Walle. 2016. “A Poor Means Test? Econometric Targeting in Africa,” NBER Working Paper 22919.

Case, Anne, Christina Paxson and Joseph Ableidinger. 2004. “Orphans in Africa: Poverty and School Enrollment,” Demography 41(3): 483-508.

Chiappori, Pierre-Andre, and Maurizio Mazzocco. 2015. "Static and Intertemporal Household Decisions,” mimeo, Department of Economics, Columbia University.

Coady, David, Margaret Grosh and John Hoddinott. 2004. Targeting Transfers in Developing Countries: Review of Lessons and Experience, Washington D.C.: World Bank.

Del Ninno, Carlo and Bradford Mills. 2015 (Eds.). Safety Nets in Africa: Effective Mechanisms to Reach the Poor and Most Vulnerable. The World Bank, Washington D.C.

Dercon, Stefan and Pramila Krishnan. 2000. “In Sickness and in Health: Risk Sharing within Households in Rural Ethiopia,” Journal of Political Economy 108(4): 688-727.

Desai, Sonalde. 1995."When are Children from Large Families Disadvantaged? Evidence from CrossNational Analyses." Population Studies 49(2): 195-210.

De Vreyer, Philippe, and Sylvie Lambert. 2016. "Intra-household Inequalities and Poverty in Senegal,” mimeo, Paris School of Economics.

Djuikom, Marie Albertine and Dominique van de Walle. 2017. “Marital Shocks and Women’s Welfare in Africa,” mimeo, World Bank, Washington, DC

Duflo, Esther, Michael Greenstone, Raymond Guiteras and Thomas Clasen. 2015. “Toilets can Work: Short and Medium Run Health Impacts of Addressing Complementarities and Externalities in Water and Sanitation,” NBER Working Paper 21521. 
Evans, David and Edward Miguel. 2007. "Orphans and Schooling in Africa: A Longitudinal Analysis,” Demography 44(1): 35-57.

Ezememari, Kene, Nazmul Chaudhury and Janet Owens. 2002. "Gender and Risk in the Design of Social Protection Interventions,” Social Protection Discussion Paper Series No. 0231, World Bank, Washington, DC.

Filmer, Deon and Lant Pritchett. 2001. “Estimating Wealth Effects Without Expenditure Data—or Tears: An Application to Educational Enrollments in States of India.” Demography 38(1): 115132.

Filmer, Deon and Lant Pritchett. 1999. “The Effect of Household Wealth on Educational Attainment: Evidence from 35 Countries.” Population and Development Review 25(1): 85-120.

Filmer, Deon and Kinnon Scott. 2012. “Assessing Asset Indices.” Demography 49(1): 359-392. Fiszbein, Ariel, and Norbert Schady. 2010. Conditional Cash Transfers for Attacking Present and Future Poverty, World Bank, Washington DC.

Grogan, Louise and Luc Moers. 2016. "Wealthier is not Healthier in Sub-Saharan Africa.” Mimeo, University of Guelph.

Haddad, Lawrence and Ravi Kanbur. 1990. "How Serious is the Neglect of Intra-Household Inequality?” Economic Journal 100: 866-881.

Haddad, Lawrence, Harold Alderman, Simon Appleton, Lina Song, and Yisehac Yohannes. 2003. “Reducing Child Malnutrition: How Far Does Income Growth Take Us?” World Bank Economic Review 17(1): 107-131.

Hoddinott, John, John Maluccio, Jere Behrman, Rafael Flores, and Reynaldo Martorell. 2008. "Effect of a Nutrition Intervention During Early Childhood on Economic Productivity in Guatemalan Adults,” Lancet 371:411-6.

Hong, Rathavuth and Rathmony Hong. 2007. “Economic Inequality and Undernutrition in Women: Multilevel Analysis of Individual, Household, and Community Levels in Cambodia.” Food and Nutrition Bulletin 28(1): 59-66.

Howe, Laura, James Hargreaves, Sabine Gabrysch, and Sharon Huttly. 2009. "Is the Wealth Index a Proxy for Consumption Expenditure? A Systematic Review.” Journal of Epidemiology and Community Health 63(11): 871-877. 
Kakwani, Nanak, Adam Wagstaff and Eddy van Doorslaer. 1997. “Socioeconomic Inequalities in Health: Measurement, Computation and Statistical Inference,” Journal of Econometrics 77(1): 87-103.

Kidd, Stephen and Emily Wylde. 2011. “Targeting the Poorest: An Assessment of the Proxy Means Test Methodology,” AusAid Research Paper, AusAid, Canberra.

Lambert, Sylvie, Martin Ravallion and Dominique van de Walle. 2014. "Intergenerational Mobility and Interpersonal Inequality in an African Economy,” Journal of Development Economics 110: 327344.

Larsen, Anna Folke, Derek Headey, William A. Masters. 2017. "Misreporting Month of Birth: Implications for Nutrition Research,” IFPRI Discussion Paper 01617.

Madise, Nyovani, Zoe Matthews, and Barrie Margetts. 1999. “Heterogeneity of Child Nutritional Status between Households: A Comparison of Six Sub-Saharan African Countries.” Population Studies 53(3): 331-43.

Manley, James, Seth Gitter, and Vanya Slavchevska. 2013. "How Effective are Cash Transfers at Improving Nutritional Status?" World Development 48: 133-155.

Moradi, Alexander. 2010. "Selective Mortality or Growth after Childhood? What Really is Key to Understand the Puzzling Tall Adult Heights in Sub-Saharan Africa?” mimeo, University of Sussex, UK.

Ngure, Francis, Brianna Reid, Jean Humphrey, Mduduzi Mbuya, Gretel Pelto and Rebecca Stoltzfus. 2014. "Water, Sanitation and Hygiene (WASH), Environmental Enteropathy, Nutrition, and Early Child Development: Making the Links,” Annals of the New York Academy of Sciences 1308(1): 118-128.

O’Donnell, Owen, Eddy van Doorslaer, Adam Wagstaff and Magnus Lindelow. 2008. Analyzing Health Equity Using Household Survey Data, World Bank.

Petrou, Stavos, and Emil Kupek. 2010. "Poverty and Childhood Undernutrition in Developing Countries: A Multi-National Cohort Study,” Social Science and Medicine 71: 1366-1373.

Pitt, Mark. 1983. "Food Preferences and Nutrition in Rural Bangladesh,” Review of Economics and Statistics LXV: 105-114.

Ravallion, Martin. 1990. “Income Effects on Undernutrition,” Economic Development and Cultural Change 38: 490-515. 
Ravallion, Martin. 1992. "Does Undernutrition Respond to Incomes and Prices? Dominance Tests for Indonesia," World Bank Economic Review 6: 109-124.

Ravallion, Martin. 2009. "How Relevant is Targeting to the Success of the Antipoverty Program?” World Bank Research Observer 24(3): 205-231.

Ravallion, Martin. 2016. The Economics of Poverty. History, Measurement, and Policy. New York: Oxford University Press.

Richard, Stephanie, Robert Black, Robert Gilman, Richard Guerrant, Gagandeep Kang, Claudio Lanata, Ka ${ }^{\circ}$ re Mølbak, Zeba Rasmussen, Bradley Sack, Palle Valentiner-Branth, William Checkley, and Childhood Infection and Malnutrition Network. 2012. "Wasting is Associated with Stunting in Early Childhood,” Journal of Nutrition: Nutritional Epidemiology 142: 1291-1296.

Ruel, Marie, Harold Alderman, and Maternal and Child Nutrition Study Group. 2013. "Nutritionsensitive Interventions and Programmes: How can they Help to Accelerate Progress in Improving Maternal and Child Nutrition?" The Lancet 382: 536-551.

Sahn, David and David Stifel. 2003. "Exploring Alternative Measures of Welfare in the Absence of Expenditure Data." Review of Income and Wealth 49: 463-489.

Sahn, David and Stephen Younger. 2009. "Measuring Intra-Household Health Inequality: Explorations Using the Body Mass Index.” Health Economics 18: S13-S36.

Smith, Lisa and Lawrence Haddad. 2015. "Reducing Child Undernutrition: Past Drivers and Priorities for the Post-MDG Era," World Development 68: 180-204.

Spears, Dean. 2013. “How Much Intergenerational Variation in Child Height Can Sanitation Explain?” Policy Research Working Paper 6351, World Bank.

Steckel, Richard. 1995. “Stature and the Standard of Living,” Journal of Economic Literature 33(4): 1903-1940.

Svedberg, Peter. 1990. “Undernutrition in Sub-Saharan Africa: Is there a Gender Bias?” Journal of Development Studies 26(3): 469-486.

Ulijaszek, Stanley J. and Deborah A. Kerr. 1999. “Anthropometric Measurement Error and the Assessment of Nutritional Status,” British Journal of Nutrition 82: 165-177.

UNICEF. 2011. Levels and Trends in Child Mortality. UNICEF and collaborating agencies, New York. van de Walle, Dominique. 2013. “Lasting Welfare Effects of Widowhood in Mali.” World Development 51: 1-19. 
Victora, Cesar. 1992. “The Association between Wasting and Stunting: An International Perspective.” Journal of Nutrition 122(5): 1105-10.

Wagstaff, Adam. 2003. "Child Health on a Dollar a Day: Some Tentative Cross-country Comparisons.” Social Science and Medicine 57(9): 1529-38.

Wagstaff, Adam, Caryn Bredenkamp, and Leander Buisman. 2014. "Progress on Global Health Goals: Are the Poor Being Left Behind?” World Bank Research Observer 29(2): 137-162.

Wagstaff, Adam and Naoko Watanabe. 2000. "Socioeconomic Inequalities in Child Malnutrition in the Developing World.” Policy Research Working Paper 2434, World Bank.

Walker, Susan, Theodore Wachs, Julie Gardner, Betsy Lozoff, Gail Wasserman, Ernesto Pollitt, and Julie Carter. 2007. "Child Development: Risk Factors for Adverse Outcomes in Developing Countries.” Lancet 369 (9556): 145-57.

Wamani, Henry, Anne Nordrehaug Åstrøm, Stefan Peterson, James K. Tumwine, and Thorkild Tylleskär. 2007. "Boys are more Stunted than Girls in Sub-Saharan Africa: a Meta-Analysis of 16 Demographic and Health Surveys.” BMC Pediatrics. 7(1): 17-27.

World Bank. 2012. World Development Report 2012: Gender Equality and Development. Washington, DC.

World Health Organization (WHO). 2016. From Promise to Impact: Ending Malnutrition by 2030. Geneva: World Health Organization.

Zere, Eyob, and Diane McIntyre. 2003. "Inequities in Under-five Child Malnutrition in South Africa." International Journal for Equity in Health 2 (1): 1. 
Figure 1: Nutritional outcomes and household wealth
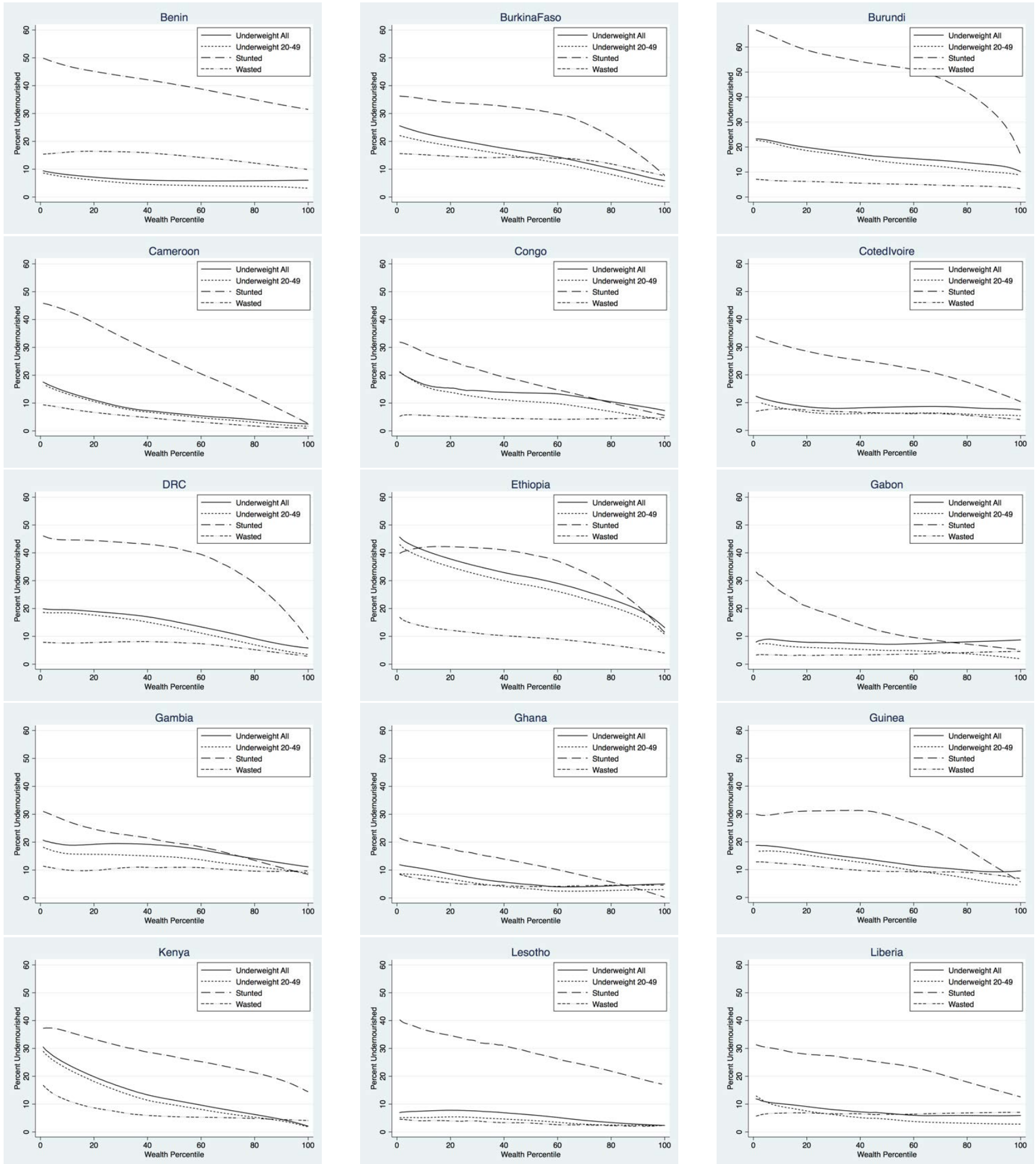

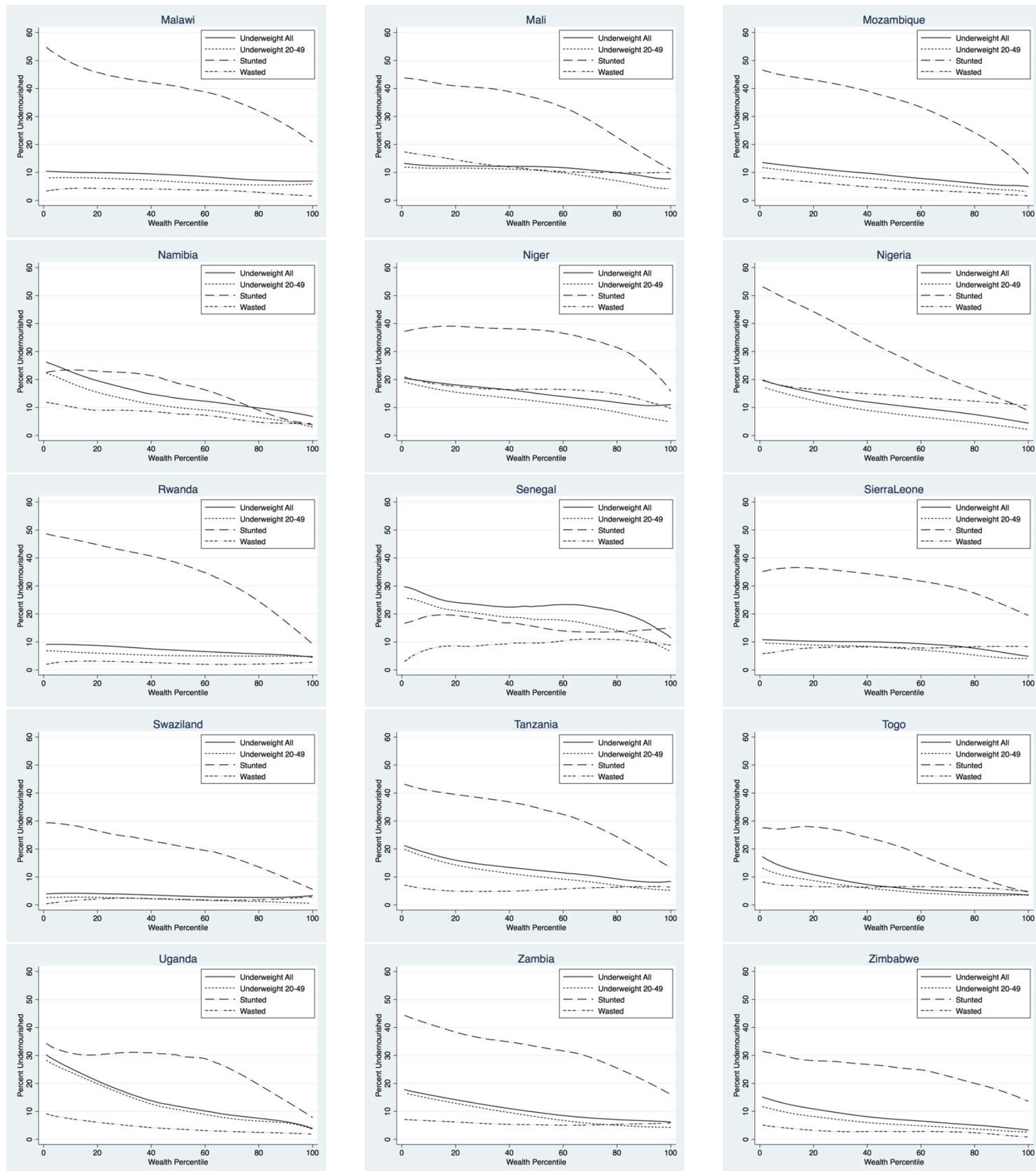

Note: The graphs show proportions of underweight women and of stunted and wasted children aged between 0 and 5 across the distribution of household wealth percentiles. Data are drawn from DHS. Observations with missing values and pregnant women have been dropped. The solid line represents women aged 15 through 49; while the dashed line represents women aged 20 through 49. Households are ranked by their wealth index and placed into wealth percentiles. A lowess regression is used to fit the lines. 


\section{Figure 2: Nutritional outcomes and household consumption}
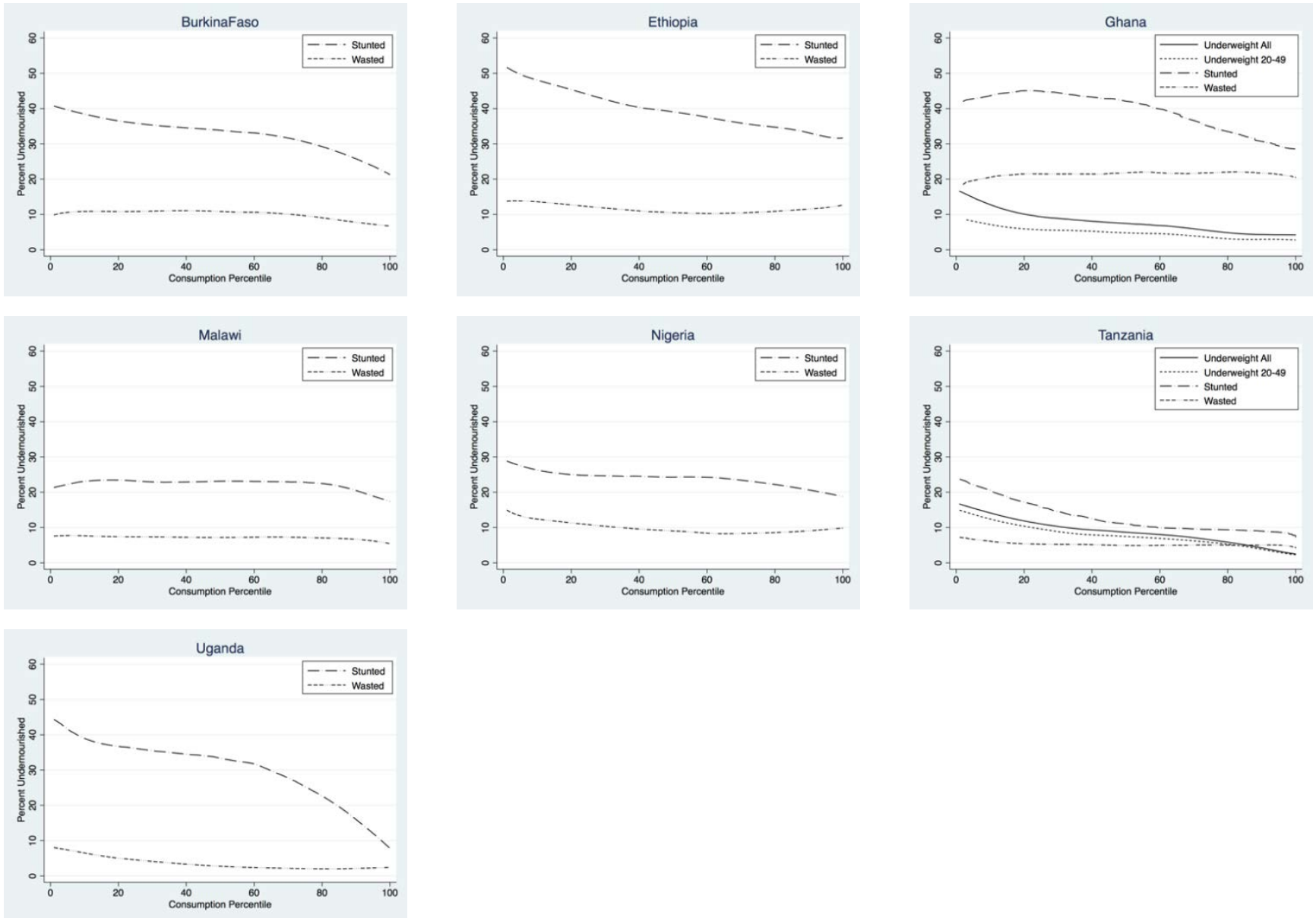

Note: The graphs show proportions of underweight women and of stunted and wasted children aged between 0 and 5 , across the distribution of per capita consumption percentiles. Data are drawn from LSMSs. Observations with missing values and pregnant women in Ghana have been dropped. The solid line represents women aged 15 through 49; while the dashed line represents women aged 20 through 49. Households are ranked by their spatially deflated per capita consumption and placed into consumption percentiles. A lowess regression is used to fit the lines. 
Figure 3: Concentration curves for undernutrition and household wealth
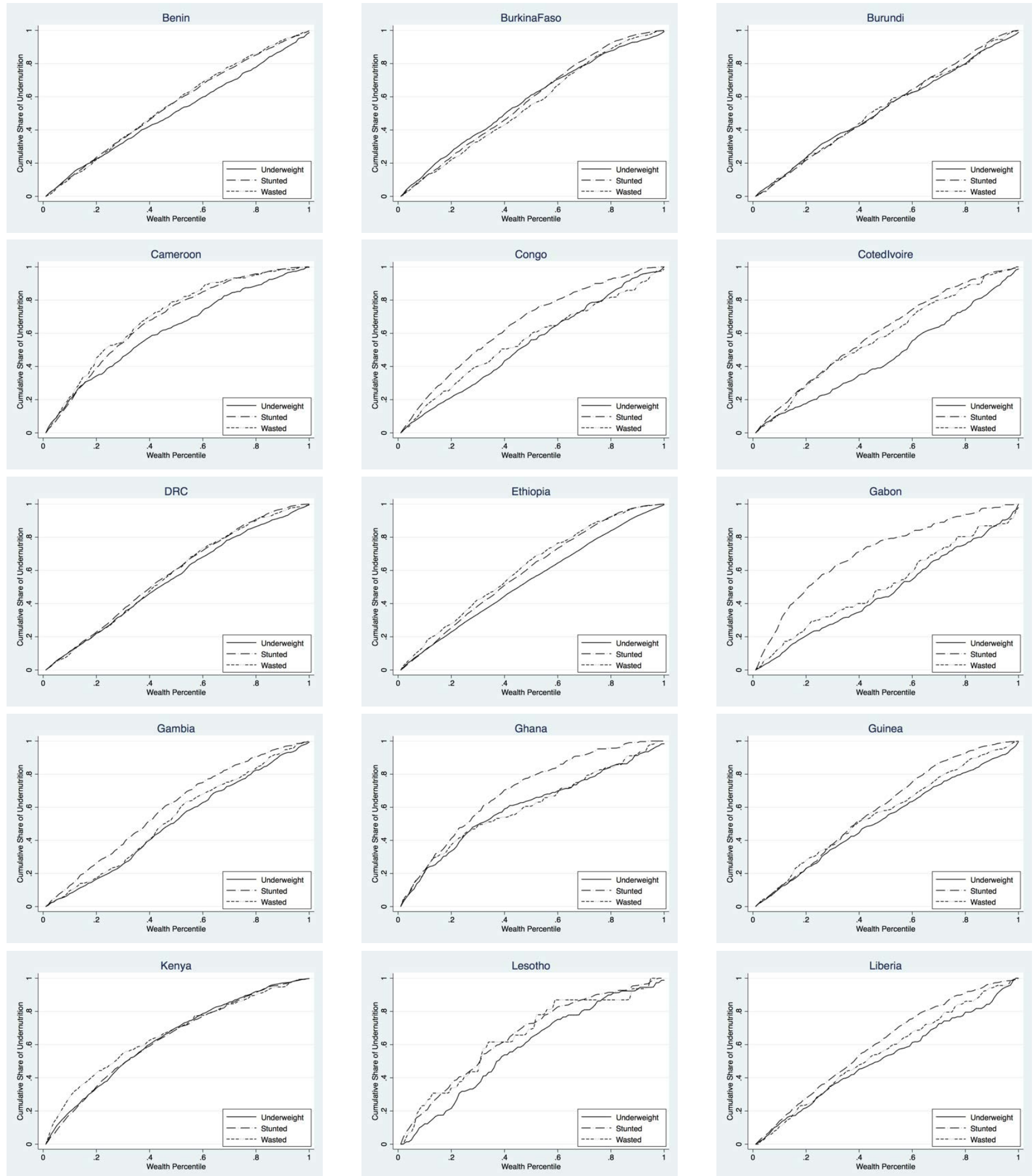

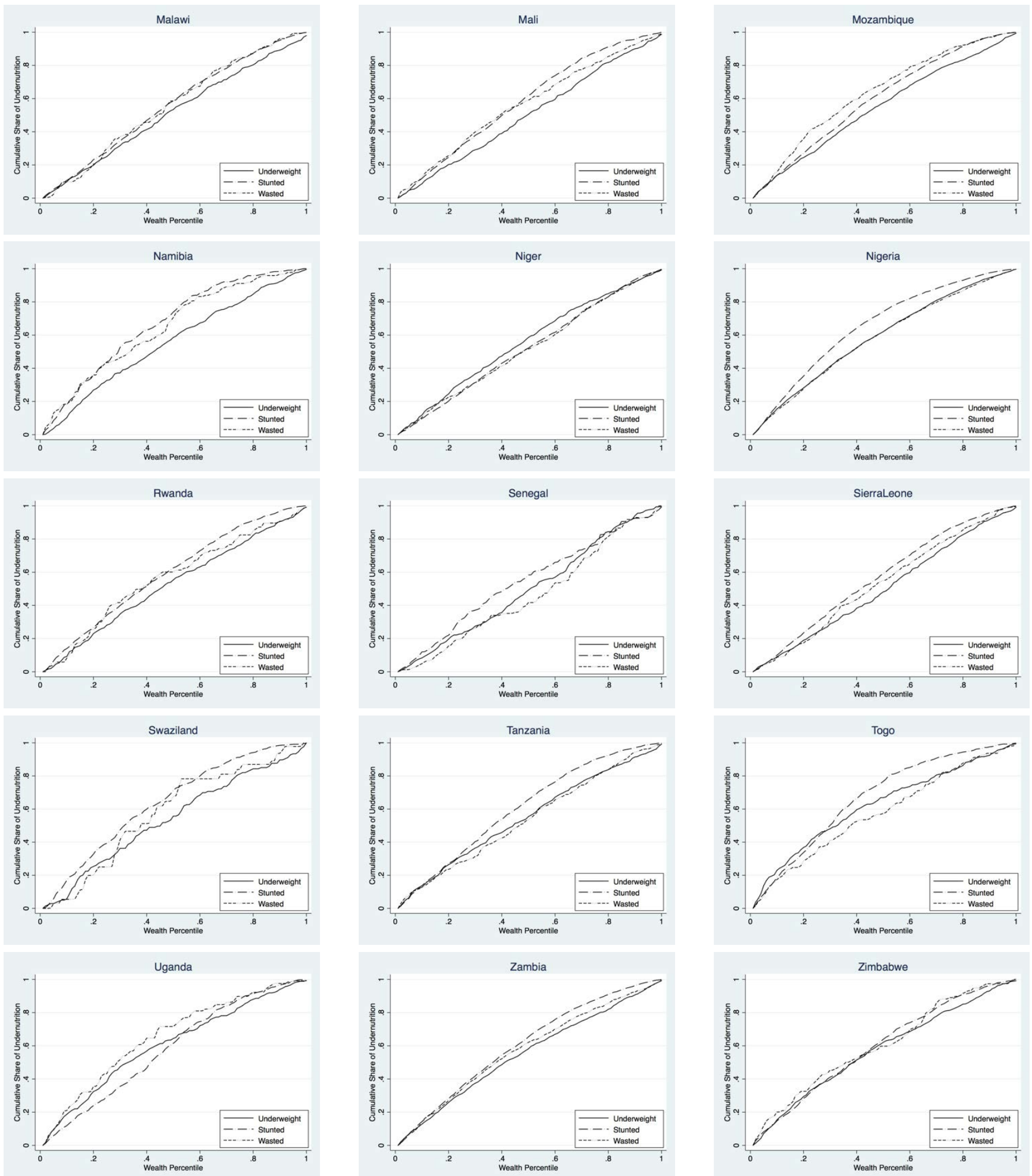

Note: The graphs show the concentration curves for the cumulative proportion of women aged 15-49 who are underweight, and children aged 0-5 who are stunted and wasted at each household wealth percentile. Data is drawn from the DHS. Observations with missing values and pregnant women have been dropped. Households are ranked by their wealth index and placed into wealth percentiles. The Stata command glcurve is used to construct the lines. 


\section{Figure 4: Concentration curves for undernutrition and household consumption}
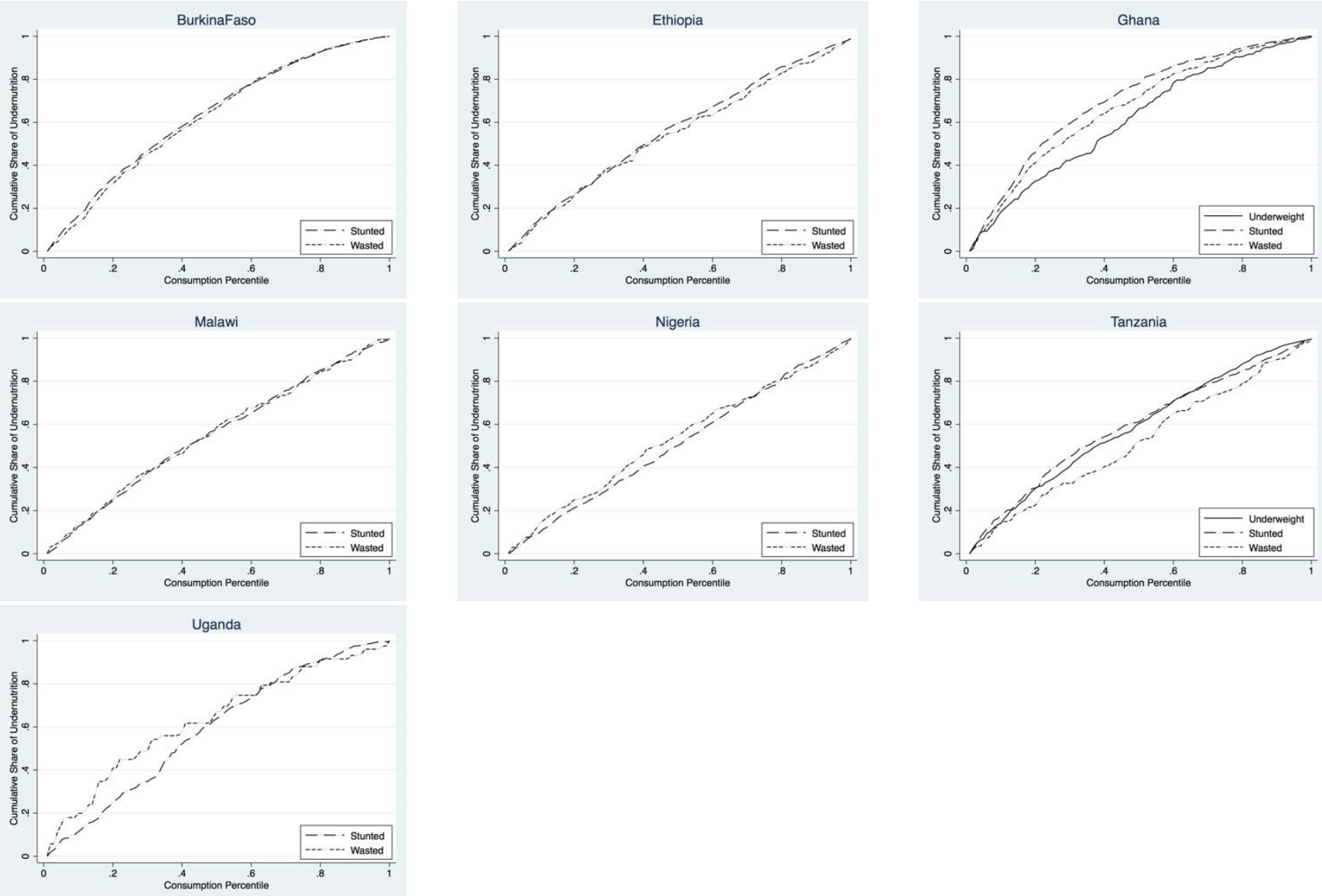

Note: The graphs show the concentration curves for the cumulative proportion of women aged 15-49 who are underweight, and children aged 0-5 who are stunted and wasted at each household consumption percentile. Data is drawn from LSMSs. Observations with missing values and pregnant women in Ghana have been dropped. Households are ranked by their spatially deflated per capita consumption and placed into consumption percentiles. The Stata command glcurve is used to construct the lines. 
Figure 5: Countries with fewer underweight women tend to have a higher proportion of those women in wealth-poor households

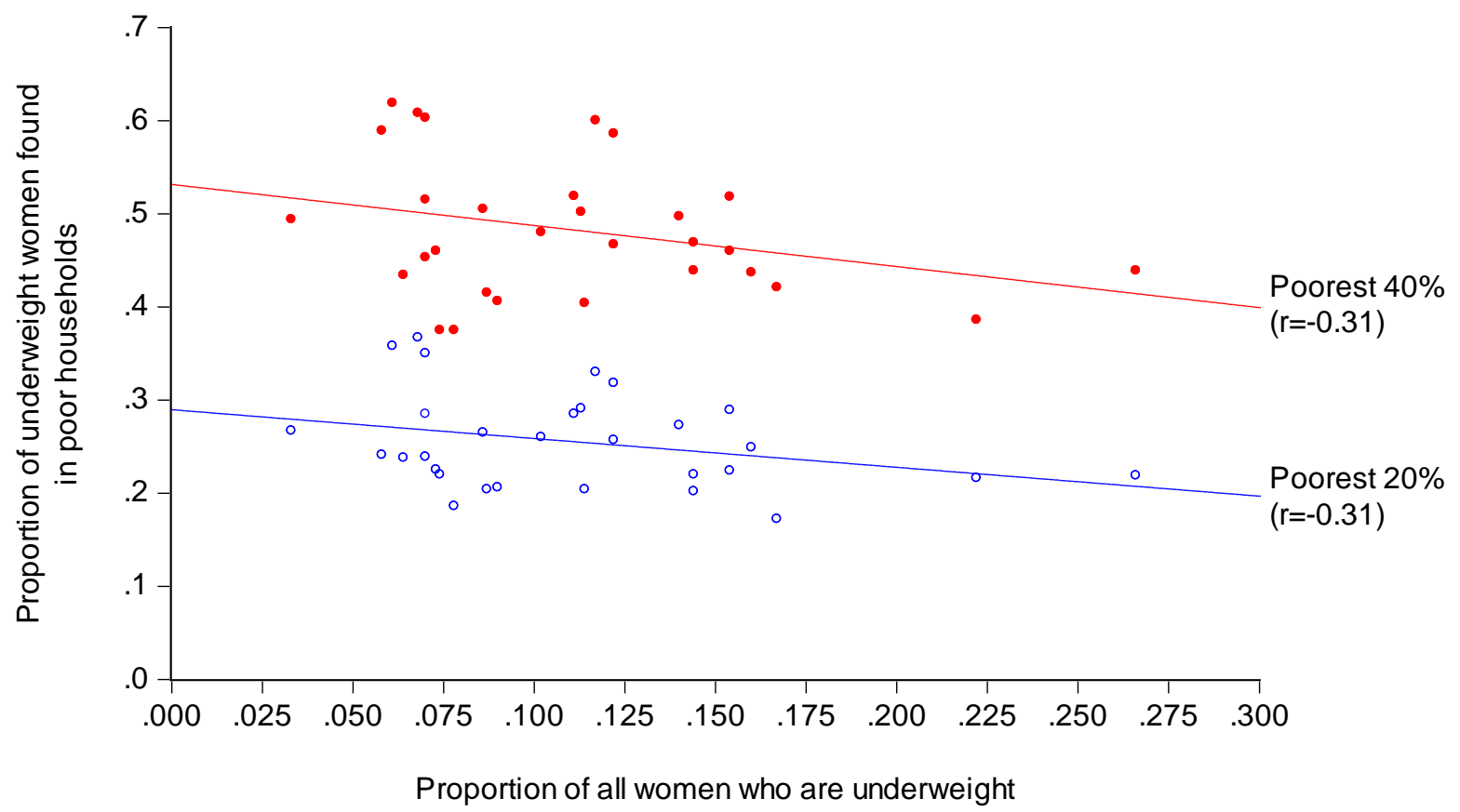

Note: The graph plots the joint probability of a woman being both underweight and in a poor household against the share of women who are underweight for each country. The actual values are given in Tables 2 and 8. 
Figure 6: Countries with fewer stunted children tend to have a higher proportion of those children in wealth-poor households

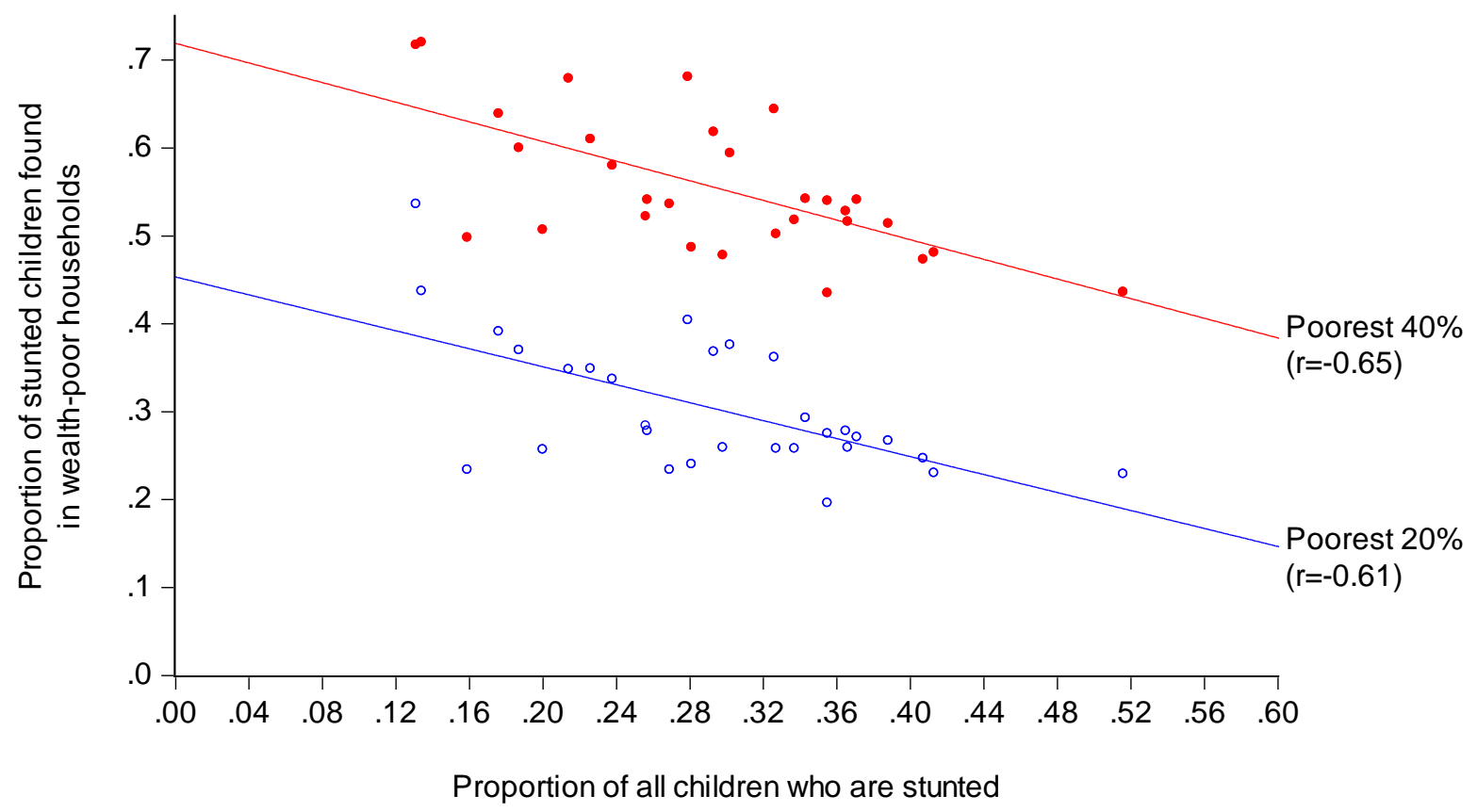

Note: The graph plots the joint probability of a child being both stunted and in a poor household against the share of children who are stunted for each country. The actual values are given in Tables 2 and 8. 
Figure 7: Countries with fewer wasted children tend to have a higher proportion of those children in wealth-poor households

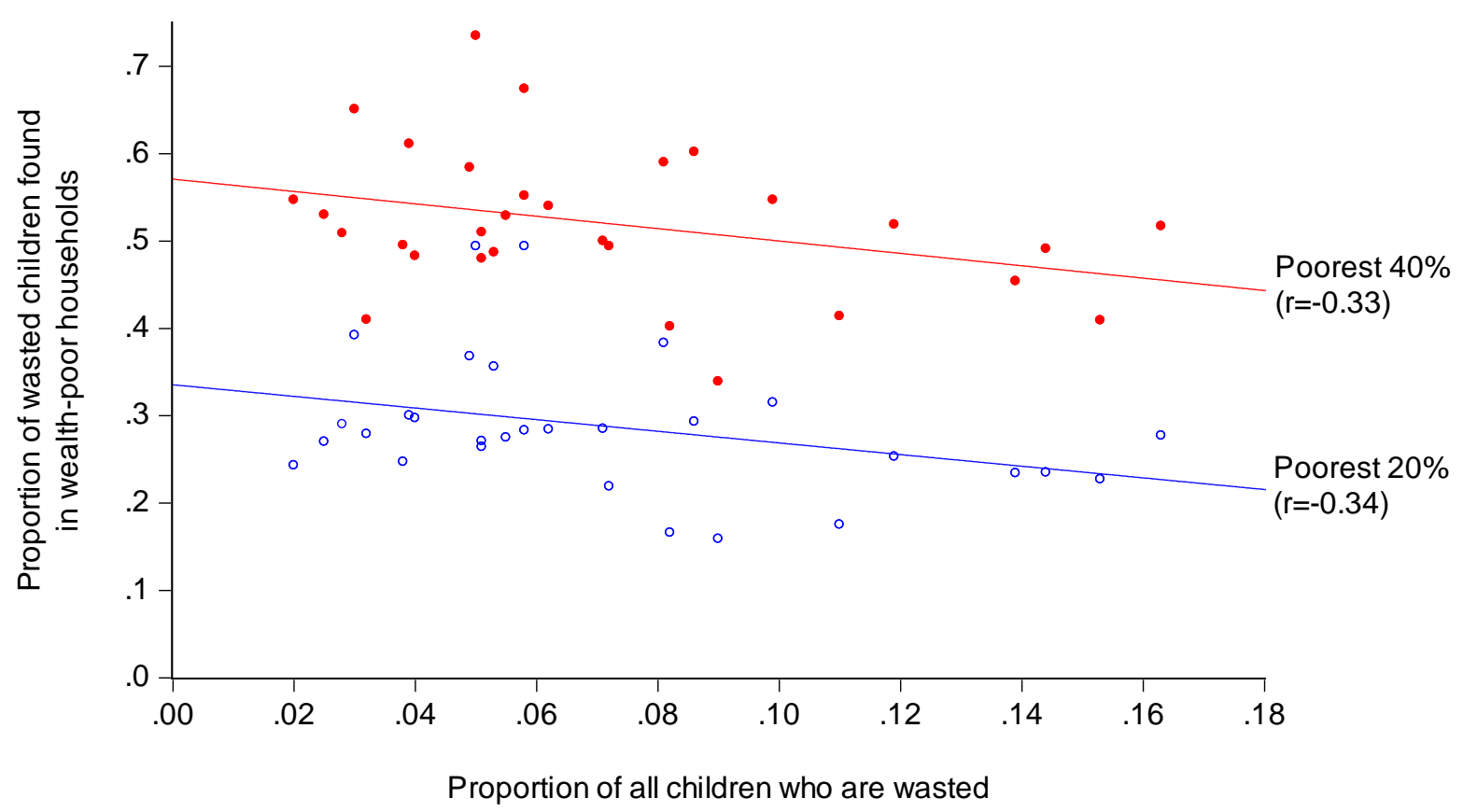

Note: The graph plots the joint probability of a child being both wasted and in a poor household against the share of children who are wasted for each country. The actual values are given in Tables 2 and 8. 
Figure 8: Health outcomes for children and household wealth
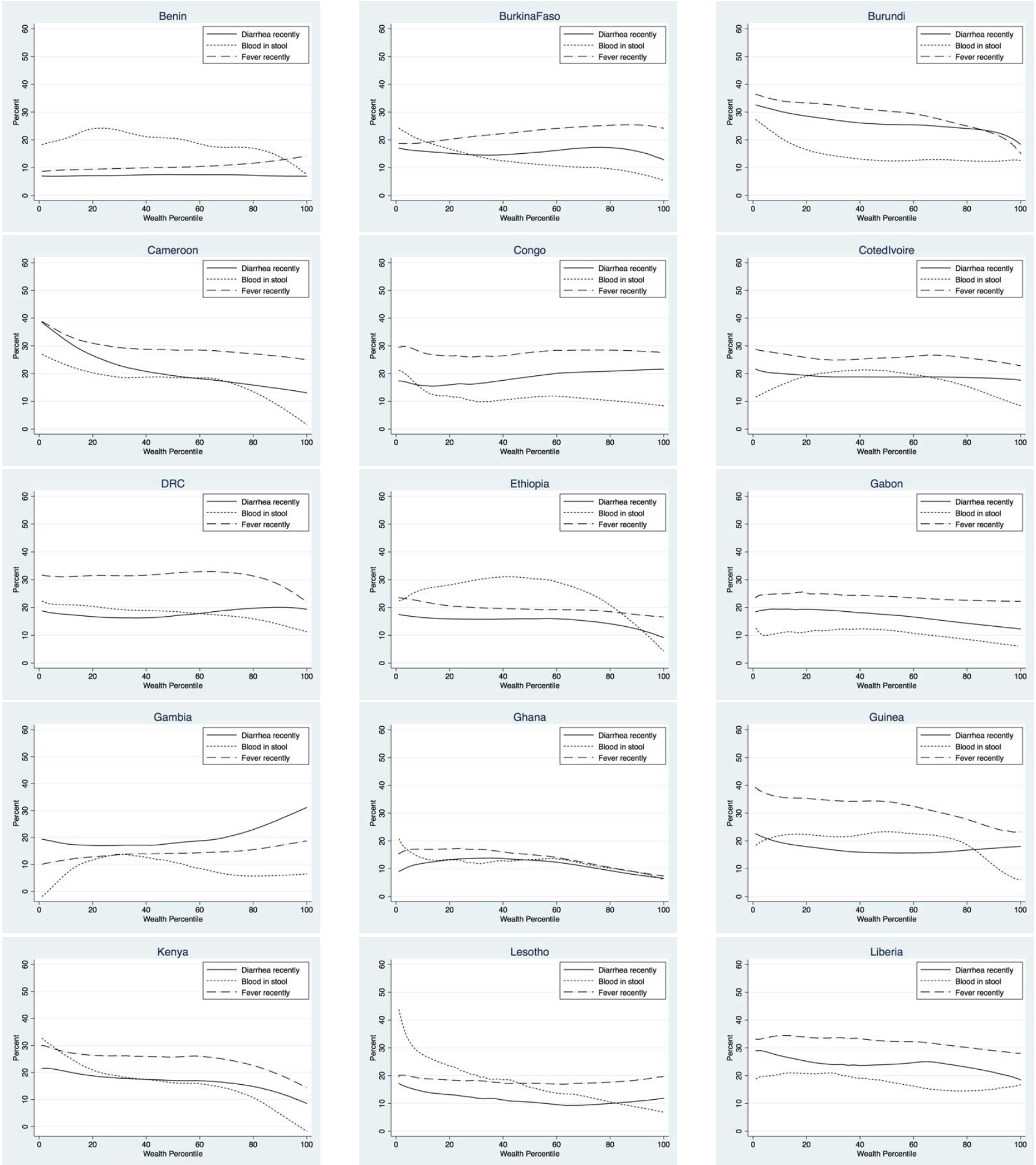

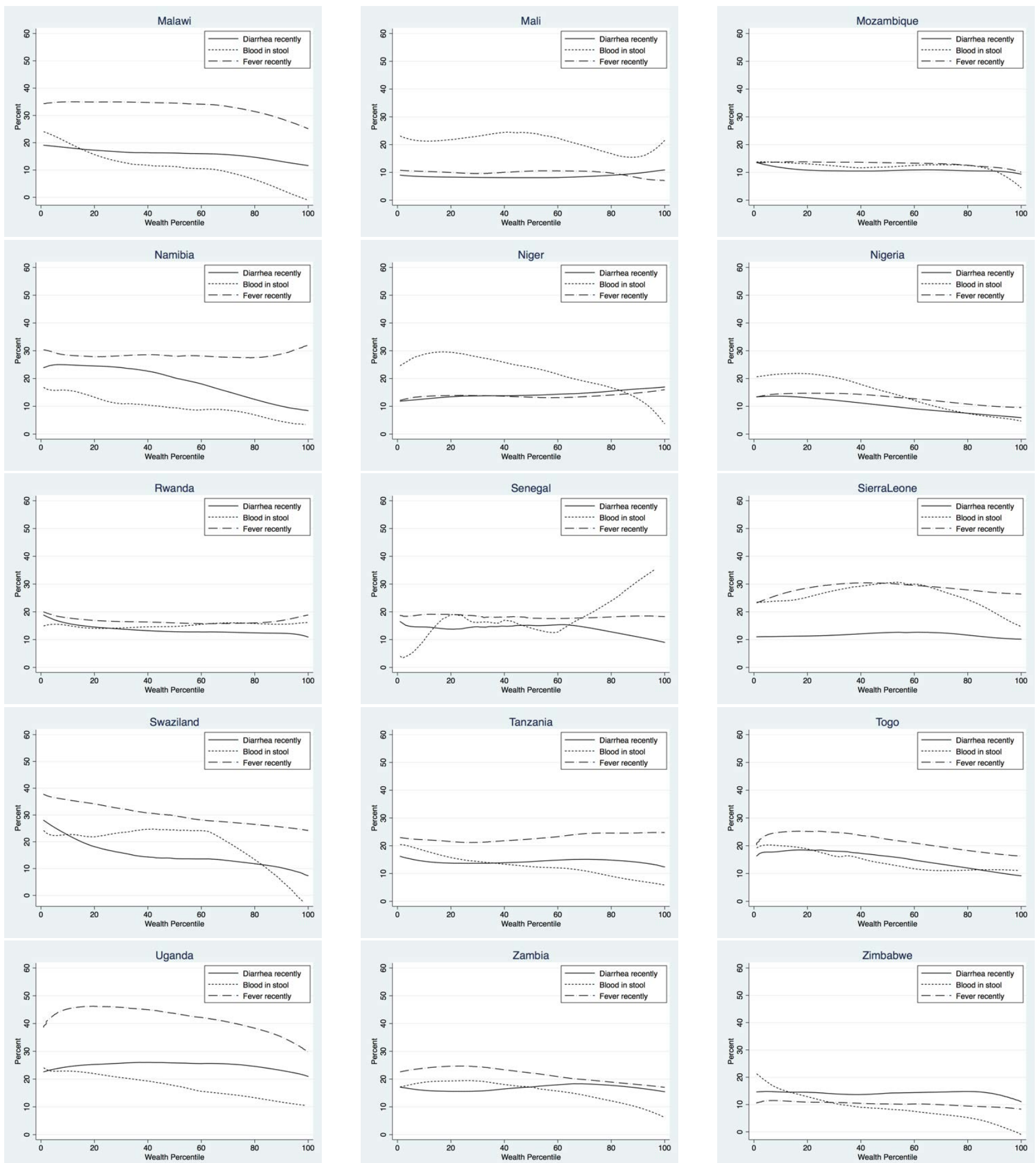

Note: The graphs show the proportion of children aged between 0 and 5 who have suffered diarrhea in the past two weeks, the proportion of children suffering from diarrhea who have had blood in their stool, and the proportion of children who have had a fever in the last two weeks across the distribution of household wealth percentiles. Data are drawn from DHS. Households are ranked by their wealth index and placed into wealth percentiles. A lowess regression is used to fit the lines. 
Table 1: Summary statistics for nutritional indicators using DHS

\begin{tabular}{|c|c|c|c|c|c|c|c|}
\hline & \multirow{2}{*}{$\begin{array}{l}\text { Underweight } \\
\text { women }\end{array}$} & \multicolumn{3}{|c|}{ Stunted children } & \multicolumn{3}{|c|}{ Wasted children } \\
\hline & & Boys & Girls & Mean & Boys & Girls & Mean \\
\hline Benin & 0.064 & 0.434 & 0.378 & 0.407 & 0.151 & 0.137 & 0.144 \\
\hline Burkina Faso & 0.154 & 0.315 & 0.279 & 0.298 & 0.150 & 0.128 & 0.139 \\
\hline Burundi & 0.160 & 0.553 & 0.478 & 0.516 & 0.051 & 0.050 & 0.051 \\
\hline Cameroon & 0.068 & 0.292 & 0.267 & 0.279 & 0.059 & 0.041 & 0.050 \\
\hline Congo & 0.144 & 0.175 & 0.200 & 0.187 & 0.046 & 0.055 & 0.051 \\
\hline Cote D'Ivoire & 0.078 & 0.258 & 0.220 & 0.238 & 0.078 & 0.065 & 0.071 \\
\hline DRC & 0.144 & 0.379 & 0.353 & 0.366 & 0.085 & 0.059 & 0.072 \\
\hline Ethiopia & 0.266 & 0.393 & 0.383 & 0.388 & 0.096 & 0.076 & 0.086 \\
\hline Gabon & 0.074 & 0.147 & 0.115 & 0.131 & 0.035 & 0.029 & 0.032 \\
\hline Gambia & 0.167 & 0.207 & 0.192 & 0.200 & 0.124 & 0.096 & 0.110 \\
\hline Ghana & 0.061 & 0.137 & 0.130 & 0.134 & 0.050 & 0.057 & 0.053 \\
\hline Guinea & 0.122 & 0.280 & 0.257 & 0.269 & 0.102 & 0.096 & 0.099 \\
\hline Kenya & 0.122 & 0.301 & 0.285 & 0.293 & 0.064 & 0.051 & 0.058 \\
\hline Lesotho & 0.058 & 0.332 & 0.274 & 0.302 & 0.039 & 0.022 & 0.030 \\
\hline Liberia & 0.073 & 0.272 & 0.238 & 0.257 & 0.059 & 0.056 & 0.058 \\
\hline Malawi & 0.087 & 0.445 & 0.382 & 0.413 & 0.040 & 0.035 & 0.038 \\
\hline Mali & 0.114 & 0.338 & 0.336 & 0.337 & 0.117 & 0.121 & 0.119 \\
\hline Mozambique & 0.086 & 0.384 & 0.359 & 0.371 & 0.052 & 0.046 & 0.049 \\
\hline Namibia & 0.140 & 0.184 & 0.169 & 0.176 & 0.108 & 0.054 & 0.081 \\
\hline Niger & 0.154 & 0.360 & 0.350 & 0.355 & 0.166 & 0.141 & 0.153 \\
\hline Nigeria & 0.111 & 0.338 & 0.314 & 0.326 & 0.169 & 0.156 & 0.163 \\
\hline Rwanda & 0.070 & 0.388 & 0.342 & 0.365 & 0.030 & 0.020 & 0.025 \\
\hline Senegal & 0.222 & 0.156 & 0.144 & 0.159 & 0.083 & 0.070 & 0.090 \\
\hline Sierra Leone & 0.090 & 0.330 & 0.324 & 0.327 & 0.082 & 0.082 & 0.082 \\
\hline Swaziland & 0.033 & 0.250 & 0.202 & 0.226 & 0.022 & 0.018 & 0.020 \\
\hline Tanzania & 0.113 & 0.373 & 0.338 & 0.355 & 0.043 & 0.038 & 0.040 \\
\hline Togo & 0.070 & 0.220 & 0.207 & 0.214 & 0.072 & 0.051 & 0.062 \\
\hline Uganda & 0.117 & 0.307 & 0.256 & 0.281 & 0.038 & 0.039 & 0.039 \\
\hline Zambia & 0.102 & 0.357 & 0.329 & 0.343 & 0.054 & 0.056 & 0.055 \\
\hline Zimbabwe & 0.070 & 0.272 & 0.239 & 0.256 & 0.032 & 0.024 & 0.028 \\
\hline Mean & 0.114 & 0.334 & 0.307 & 0.321 & 0.092 & 0.081 & 0.086 \\
\hline
\end{tabular}

Note: Observations with missing values and pregnant women are dropped. Means are population weighted. Women between 15 and 49 years of age and children between 0 and 5 years of age are included. A woman is underweight if she has a BMI less than or equal to 18.5. A child is stunted if she is two standard deviations below median height-for-age and wasted if she is two standard deviations below median weight-for-height. 
Table 2: Summary statistics for nutritional indicators using LSMS

\begin{tabular}{lccccccc}
\hline & $\begin{array}{c}\text { Underweight } \\
\text { women }\end{array}$ & Boys & Girls & Mean & Boys & Girls & Mean \\
\hline Burkina Faso & n.a. & 0.381 & 0.301 & 0.342 & 0.127 & 0.092 & 0.110 \\
Ethiopia & n.a. & 0.410 & 0.401 & 0.406 & 0.133 & 0.109 & 0.121 \\
Ghana & 0.081 & 0.388 & 0.382 & 0.385 & 0.209 & 0.196 & 0.202 \\
Malawi & n.a. & 0.281 & 0.238 & 0.260 & 0.080 & 0.079 & 0.079 \\
Nigeria & n.a. & 0.242 & 0.225 & 0.234 & 0.120 & 0.092 & 0.106 \\
Tanzania & 0.095 & 0.138 & 0.102 & 0.120 & 0.043 & 0.054 & 0.048 \\
Uganda & n.a. & 0.335 & 0.230 & 0.280 & 0.035 & 0.037 & 0.036 \\
\hline Mean & n.a. & 0.307 & 0.268 & 0.287 & 0.100 & 0.087 & 0.093 \\
\hline
\end{tabular}

Note: Data are drawn from LSMSs. Observations with missing values have been dropped. Means are population weighted. Women between 15 and 49 years of age and children between 0 and 5 years of age are included in the sample. A woman is underweight if she has a BMI less than or equal to 18.5. A child is stunted if she is two standard deviations below median height-for-age and wasted if she is two standard deviations below median weight-for-height. 


\section{Table 3: Incidence of undernutrition for countries with data on male BMI}

\begin{tabular}{|c|c|c|c|c|c|c|c|c|c|c|c|c|}
\hline & \multicolumn{2}{|c|}{ Underweight } & \multicolumn{5}{|c|}{ Male head is underweight } & \multicolumn{5}{|c|}{ Male head is not underweight } \\
\hline & \multirow[t]{2}{*}{ Men } & \multirow[t]{2}{*}{ Women } & \multirow{2}{*}{$\begin{array}{l}\text { Underweight } \\
\text { women }\end{array}$} & \multicolumn{2}{|c|}{ Stunted children } & \multicolumn{2}{|c|}{ Wasted children } & \multirow{2}{*}{$\begin{array}{l}\text { Underweight } \\
\text { women }\end{array}$} & \multicolumn{2}{|c|}{ Stunted children } & \multicolumn{2}{|c|}{ Wasted children } \\
\hline & & & & Boys & Girls & Boys & Girls & & Boys & Girls & Boys & Girls \\
\hline \multirow[t]{2}{*}{ Ethiopia } & 0.371 & 0.266 & 0.333 & 0.398 & 0.375 & 0.142 & 0.100 & 0.255 & 0.371 & 0.351 & 0.073 & 0.063 \\
\hline & & & $(0.333)$ & $(0.310)$ & $(0.266)$ & $(0.451)$ & $(0.351)$ & $(0.667)$ & $(0.690)$ & $(0.734)$ & $(0.549)$ & $(0.649)$ \\
\hline \multirow[t]{2}{*}{ Ghana } & 0.104 & 0.061 & 0.166 & 0.266 & 0.193 & 0.092 & 0.107 & 0.057 & 0.117 & 0.130 & 0.044 & 0.063 \\
\hline & & & $(0.141)$ & $(0.127)$ & $(0.073)$ & (0.119) & $(0.083)$ & (0.859) & $(0.873)$ & $(0.927)$ & $(0.881)$ & $(0.917)$ \\
\hline \multirow[t]{2}{*}{ Lesotho } & 0.188 & 0.062 & 0.067 & 0.541 & 0.220 & 0.065 & 0.016 & 0.044 & 0.259 & 0.246 & 0.033 & 0.026 \\
\hline & & & $(0.136)$ & $(0.212)$ & $(0.113)$ & $(0.204)$ & $(0.082)$ & $(0.864)$ & (0.788) & (0.887) & $(0.796)$ & (0.918) \\
\hline \multirow[t]{2}{*}{ Namibia } & 0.232 & 0.137 & 0.265 & 0.207 & 0.219 & 0.118 & 0.000 & 0.102 & 0.172 & 0.170 & 0.085 & 0.049 \\
\hline & & & $(0.266)$ & (0.193) & $(0.169)$ & $(0.214)$ & $(0.000)$ & $(0.734)$ & $(0.807)$ & $(0.831)$ & $(0.786)$ & (1.000) \\
\hline \multirow[t]{2}{*}{ Rwanda } & 0.158 & 0.073 & 0.129 & 0.422 & 0.333 & 0.069 & 0.036 & 0.059 & 0.382 & 0.350 & 0.021 & 0.013 \\
\hline & & & $(0.213)$ & $(0.107)$ & $(0.096)$ & $(0.262)$ & $(0.238)$ & $(0.787)$ & $(0.893)$ & $(0.904)$ & $(0.738)$ & $(0.762)$ \\
\hline \multirow[t]{2}{*}{ Senegal } & 0.275 & 0.216 & 0.306 & 0.273 & 0.193 & 0.100 & 0.076 & 0.211 & 0.182 & 0.181 & 0.067 & 0.075 \\
\hline & & & (0.195) & $(0.180)$ & $(0.154)$ & (0.179) & $(0.147)$ & $(0.805)$ & $(0.820)$ & $(0.846)$ & $(0.821)$ & (0.853) \\
\hline \multirow[t]{2}{*}{$\begin{array}{l}\text { Sierra } \\
\text { Leone }\end{array}$} & 0.155 & 0.091 & 0.144 & 0.267 & 0.288 & 0.103 & 0.063 & 0.085 & 0.279 & 0.279 & 0.060 & 0.061 \\
\hline & & & $(0.128)$ & $(0.070)$ & $(0.082)$ & $(0.118)$ & $(0.082)$ & $(0.872)$ & $(0.930)$ & $(0.918)$ & $(0.882)$ & $(0.918)$ \\
\hline \multirow[t]{2}{*}{ Mean } & 0.24 & 0.159 & 0.279 & 0.376 & 0.333 & 0.126 & 0.083 & 0.145 & 0.300 & 0.288 & 0.057 & 0.053 \\
\hline & & & $(0.279)$ & $(0.217)$ & $(0.182)$ & $(0.328)$ & $(0.230)$ & $(0.721)$ & $(0.783)$ & $(0.818)$ & $(0.672)$ & $(0.770)$ \\
\hline
\end{tabular}

Note: The table shows the proportion of undernourished women and children in male headed households separated by the nutritional status of the household head. The figures in parentheses are the shares of those women or children who are undernourished found in each of the two groups of households according to whether the male head is underweight. Men and women are between 15 and 49 years of age. Male heads of household are also restricted to 15 and 49 years of age. Children are between 0 and 5 years of age. 
Table 4: Regression coefficients of individual nutritional outcomes on the DHS household wealth index and household consumption per person

\begin{tabular}{|c|c|c|c|c|c|c|}
\hline & \multicolumn{3}{|c|}{ DHS } & \multicolumn{3}{|c|}{ LSMS } \\
\hline & BMI & Height-for-age & $\begin{array}{c}\text { Weight-for- } \\
\text { height }\end{array}$ & BMI & Height-for-age & $\begin{array}{c}\text { Weight-for- } \\
\text { height }\end{array}$ \\
\hline Benin & $0.194^{* * *}$ & $0.189^{* * *}$ & $0.080^{* * *}$ & & & \\
\hline Burkina Faso & $0.279 * * *$ & $0.281^{* * *}$ & $0.097 * * *$ & $\mathrm{n} / \mathrm{a}$ & $0.377 * * *$ & -0.016 \\
\hline Burundi & $0.242^{* * *}$ & $0.505^{* * *}$ & $0.115^{* * *}$ & & & \\
\hline Cameroon & $0.285^{* * *}$ & $0.451^{* * *}$ & $0.257 * * *$ & & & \\
\hline Congo & $0.265^{* * *}$ & $0.292^{* * *}$ & $0.051^{* *}$ & & & \\
\hline Cote D'Ivoire & $0.203^{* * *}$ & $0.279 * * *$ & 0.043 & & & \\
\hline DRC & $0.276^{* * *}$ & $0.378^{* * *}$ & $0.073 * * *$ & & & \\
\hline Ethiopia & $0.352 * * *$ & $0.374^{* * *}$ & $0.229 * * *$ & $\mathrm{n} / \mathrm{a}$ & 0.037 & 0.025 \\
\hline Gabon & $0.182 * * *$ & $0.397 * * *$ & $0.056 * *$ & & & \\
\hline Gambia & $0.208^{* * *}$ & $0.297 * * *$ & $0.061^{* *}$ & & & \\
\hline Ghana & $0.385^{* * *}$ & $0.299 * * *$ & $0.070 * * *$ & $0.120 * * *$ & $0.178^{* *}$ & 0.172 \\
\hline Guinea & $0.284^{* * *}$ & $0.285^{* * *}$ & 0.023 & & & \\
\hline Kenya & $0.331^{* * *}$ & $0.257 * * *$ & $0.210^{* * *}$ & & & \\
\hline Lesotho & $0.263^{* * *}$ & $0.182^{* * *}$ & $0.091^{*}$ & & & \\
\hline Liberia & $0.182^{* * *}$ & $0.183^{* * *}$ & -0.024 & & & \\
\hline Malawi & $0.197 * * *$ & $0.224^{* * *}$ & $0.072 * * *$ & $\mathrm{n} / \mathrm{a}$ & $0.103 * *$ & 0.004 \\
\hline Mali & $0.025^{* * *}$ & $0.039 * * *$ & 0.002 & $\mathrm{n} / \mathrm{a}$ & 0.044 & 0.006 \\
\hline Mozambique & $0.344^{* * *}$ & $0.372^{* * *}$ & $0.156^{* * *}$ & & & \\
\hline Namibia & $0.289 * * *$ & $0.323^{* * *}$ & $0.217 * * *$ & & & \\
\hline Niger & $0.268^{* * *}$ & $0.254 * * *$ & $0.119 * * *$ & & & \\
\hline Nigeria & $0.291^{* * *}$ & $0.566 * * *$ & $0.042 * * *$ & $\mathrm{n} / \mathrm{a}$ & $0.450 * * *$ & $0.200 * * *$ \\
\hline Rwanda & $0.211^{* * *}$ & $0.395 * * *$ & 0.026 & & & \\
\hline Senegal & $0.157^{* * *}$ & $0.110^{* * *}$ & -0.025 & & & \\
\hline Sierra Leone & $0.189 * * *$ & $0.253^{* * *}$ & 0.027 & & & \\
\hline Swaziland & $0.174 * * *$ & $0.305^{* * *}$ & $0.115^{* * *}$ & & & \\
\hline Tanzania & $0.295^{* * *}$ & $0.303^{* * *}$ & -0.022 & $0.213^{* * *}$ & $0.111^{* *}$ & 0.036 \\
\hline Togo & $0.323^{* * *}$ & $0.319 * * *$ & $0.073^{* *}$ & & & \\
\hline Uganda & $0.364 * * *$ & $0.278^{* * *}$ & $0.175^{* * *}$ & & & \\
\hline Zambia & $0.284^{* * *}$ & $0.255^{* * *}$ & $0.070 * * *$ & & & \\
\hline Zimbabwe & $0.311^{* * *}$ & $0.147 * * *$ & $0.151^{* * *}$ & & & \\
\hline
\end{tabular}

Note: The table gives coefficients from a regression of standardized nutritional outcomes on the wealth index or standardized consumption per capita. Robust standard errors are used; * prob. $<.10 * *$ prob. $<.05$ *** prob. $<.01$. 
Table 5: Proportion of undernourished individuals who fall into the poorest $20 \%$ and $40 \%$ of the household wealth distribution

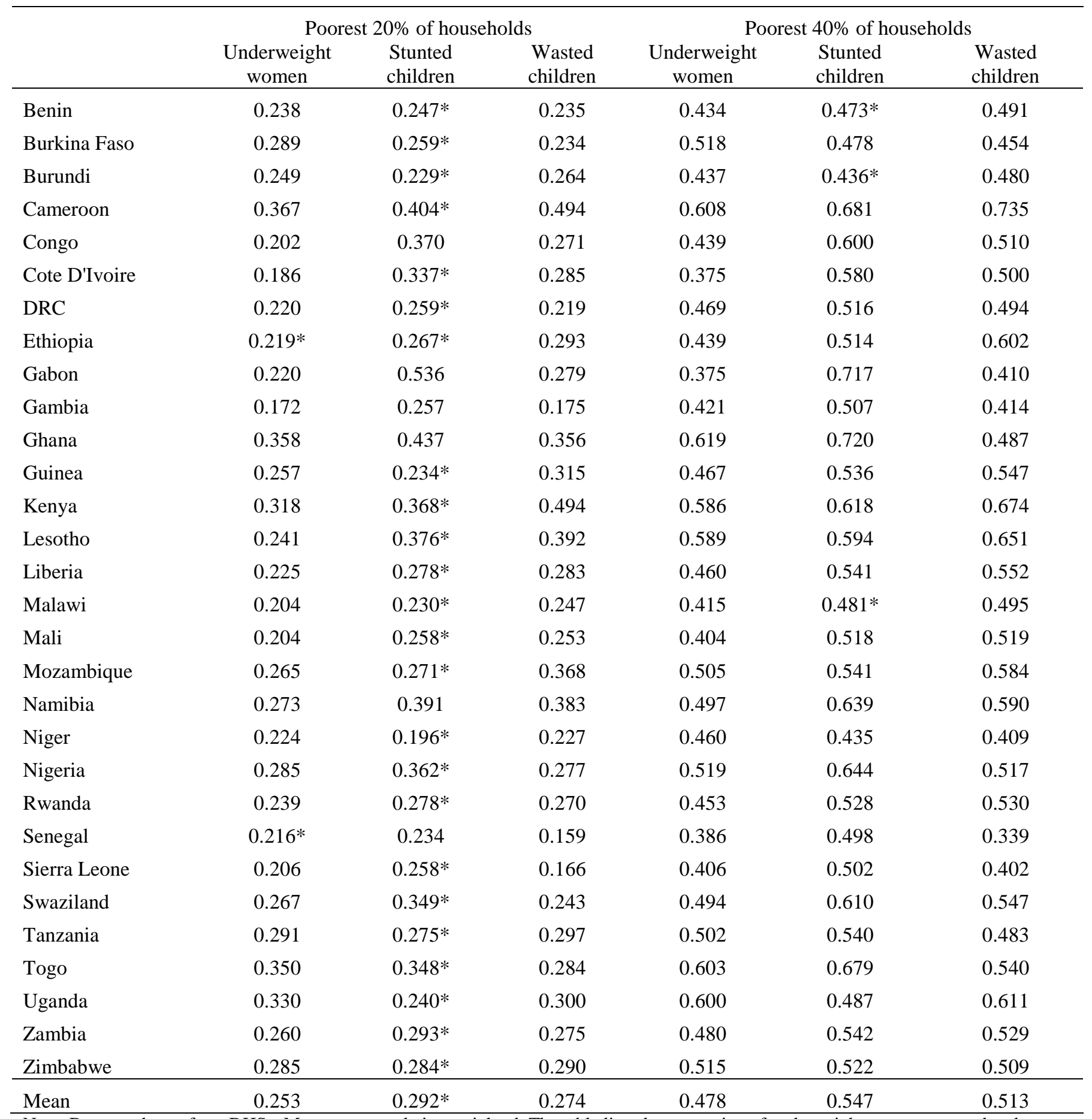

Note: Data are drawn from DHSs. Means are population weighted. The table lists the proportion of underweight women, stunted and wasted children who fall below the bottom 20th and 40th percentiles of the household wealth distribution. For example, 23.8 percent of underweight women live in households in the bottom 20th percentile of household wealth in Benin. Cases marked * are those in which the undernutrition rate exceeds the corresponding wealth poverty rate, implying that the conditional probability has an upper bound less than unity when all of the wealth poor are undernourished. 
Table 6: Proportion of undernourished individuals who fall into the poorest $20 \%$ and $40 \%$ of the household consumption per capita distribution

\begin{tabular}{|c|c|c|c|c|c|c|c|c|c|c|}
\hline & \multicolumn{3}{|c|}{ Poorest $20 \%$ of households } & \multicolumn{3}{|c|}{ Poorest $40 \%$ of households } & \multicolumn{3}{|c|}{ Poorest households by Poverty Rate } & \multirow[b]{2}{*}{$\begin{array}{c}\text { Poverty } \\
\text { rate }\end{array}$} \\
\hline & $\begin{array}{c}\text { Underweight } \\
\text { women }\end{array}$ & $\begin{array}{l}\text { Stunted } \\
\text { children }\end{array}$ & $\begin{array}{l}\text { Wasted } \\
\text { children }\end{array}$ & $\begin{array}{c}\text { Underweight } \\
\text { women }\end{array}$ & $\begin{array}{l}\text { Stunted } \\
\text { children }\end{array}$ & $\begin{array}{l}\text { Wasted } \\
\text { children }\end{array}$ & $\begin{array}{c}\text { Underweight } \\
\text { women }\end{array}$ & $\begin{array}{l}\text { Stunted } \\
\text { children }\end{array}$ & $\begin{array}{l}\text { Wasted } \\
\text { children }\end{array}$ & \\
\hline Burkina Faso & & $0.352 *$ & 0.310 & & 0.597 & 0.556 & & 0.591 & 0.549 & 0.553 \\
\hline Ethiopia & & $0.276^{*}$ & 0.304 & & $0.502 *$ & 0.517 & & $0.387^{*}$ & 0.432 & 0.335 \\
\hline Ghana & 0.297 & $0.479 *$ & $0.392 *$ & 0.484 & 0.703 & 0.642 & 0.256 & $0.403^{*}$ & 0.341 & 0.253 \\
\hline Malawi & & $0.253^{*}$ & 0.273 & & 0.505 & 0.466 & & 0.701 & 0.706 & 0.709 \\
\hline Nigeria & & $0.258^{*}$ & 0.309 & & 0.507 & 0.604 & & 0.552 & 0.657 & 0.535 \\
\hline Tanzania & 0.348 & 0.512 & 0.382 & 0.574 & 0.689 & 0.637 & 0.539 & 0.642 & 0.546 & 0.466 \\
\hline Uganda & & $0.272^{*}$ & 0.269 & & 0.562 & 0.599 & & 0.379 & 0.478 & 0.332 \\
\hline Mean & 0.340 & $0.326 *$ & 0.325 & 0.559 & 0.560 & 0.566 & 0.492 & 0.471 & 0.488 & 0.418 \\
\hline
\end{tabular}

Note: Data are drawn from LSMSs. Means are population weighted. The table lists the proportion of underweight women, stunted and wasted children who live in households ranked in the bottom 20th and 40th percentiles of the household consumption per capita distribution, along with the proportion who live in households with per capita consumption below the $\$ 1.90$ per day poverty line. Cases marked * are those in which the undernutrition rate exceeds the corresponding wealth poverty rate, implying that the conditional probability has an upper bound less than unity when all of the wealth poor are undernourished. 
Table 7: Joint probabilities of being undernourished and wealth poor

\begin{tabular}{|c|c|c|c|c|c|c|}
\hline & \multicolumn{3}{|c|}{ Poorest $20 \%$ of households } & \multicolumn{3}{|c|}{ Poorest $40 \%$ of households } \\
\hline & $\begin{array}{c}\text { Underweight } \\
\text { women }\end{array}$ & $\begin{array}{l}\text { Stunted } \\
\text { children }\end{array}$ & $\begin{array}{r}\text { Wasted } \\
\text { children }\end{array}$ & $\begin{array}{c}\text { Underweight } \\
\text { women }\end{array}$ & $\begin{array}{r}\text { Stunted } \\
\text { children }\end{array}$ & $\begin{array}{r}\text { Wasted } \\
\text { children }\end{array}$ \\
\hline Benin & 0.015 & 0.100 & 0.034 & 0.028 & 0.192 & 0.071 \\
\hline Burkina Faso & 0.044 & 0.077 & 0.033 & 0.080 & 0.142 & 0.063 \\
\hline Burundi & 0.040 & 0.118 & 0.013 & 0.070 & 0.225 & 0.024 \\
\hline Cameroon & 0.025 & 0.113 & 0.025 & 0.042 & 0.190 & 0.036 \\
\hline Congo & 0.029 & 0.069 & 0.014 & 0.063 & 0.112 & 0.026 \\
\hline Cote D'Ivoire & 0.015 & 0.080 & 0.020 & 0.029 & 0.138 & 0.036 \\
\hline DRC & 0.032 & 0.095 & 0.016 & 0.068 & 0.189 & 0.036 \\
\hline Ethiopia & 0.058 & 0.104 & 0.025 & 0.117 & 0.199 & 0.052 \\
\hline Gabon & 0.016 & 0.070 & 0.009 & 0.028 & 0.094 & 0.013 \\
\hline Gambia & 0.029 & 0.051 & 0.019 & 0.070 & 0.101 & 0.046 \\
\hline Ghana & 0.022 & 0.058 & 0.019 & 0.038 & 0.096 & 0.026 \\
\hline Guinea & 0.032 & 0.063 & 0.031 & 0.057 & 0.144 & 0.054 \\
\hline Kenya & 0.039 & 0.108 & 0.028 & 0.071 & 0.181 & 0.039 \\
\hline Lesotho & 0.014 & 0.114 & 0.012 & 0.034 & 0.180 & 0.020 \\
\hline Liberia & 0.016 & 0.071 & 0.016 & 0.033 & 0.139 & 0.032 \\
\hline Malawi & 0.018 & 0.095 & 0.009 & 0.036 & 0.199 & 0.019 \\
\hline Mali & 0.023 & 0.087 & 0.030 & 0.046 & 0.174 & 0.062 \\
\hline Mozambique & 0.023 & 0.101 & 0.018 & 0.043 & 0.201 & 0.029 \\
\hline Namibia & 0.038 & 0.069 & 0.031 & 0.070 & 0.113 & 0.047 \\
\hline Niger & 0.034 & 0.070 & 0.035 & 0.071 & 0.155 & 0.063 \\
\hline Nigeria & 0.032 & 0.118 & 0.045 & 0.058 & 0.210 & 0.084 \\
\hline Rwanda & 0.017 & 0.102 & 0.007 & 0.032 & 0.193 & 0.013 \\
\hline Senegal & 0.048 & 0.055 & 0.024 & 0.085 & 0.107 & 0.041 \\
\hline Sierra Leone & 0.018 & 0.084 & 0.014 & 0.036 & 0.164 & 0.033 \\
\hline Swaziland & 0.009 & 0.079 & 0.005 & 0.016 & 0.138 & 0.011 \\
\hline Tanzania & 0.033 & 0.098 & 0.012 & 0.057 & 0.192 & 0.019 \\
\hline Togo & 0.024 & 0.074 & 0.018 & 0.042 & 0.145 & 0.033 \\
\hline Uganda & 0.039 & 0.067 & 0.012 & 0.070 & 0.137 & 0.024 \\
\hline Zambia & 0.027 & 0.101 & 0.015 & 0.049 & 0.186 & 0.029 \\
\hline Zimbabwe & 0.020 & 0.073 & 0.008 & 0.036 & 0.133 & 0.014 \\
\hline Mean & 0.029 & 0.094 & 0.024 & 0.054 & 0.176 & 0.044 \\
\hline Corre. coeff. & 0.897 & 0.732 & 0.882 & 0.956 & 0.910 & 0.963 \\
\hline $\begin{array}{l}\text { Elasticity of joint } \\
\text { to marginal }\end{array}$ & $\begin{array}{c}0.873 \\
(0.079)\end{array}$ & $\begin{array}{c}0.511 \\
(0.087)\end{array}$ & $\begin{array}{c}0.872 \\
(0.079)\end{array}$ & $\begin{array}{c}0.905 \\
(0.060)\end{array}$ & $\begin{array}{c}0.681 \\
(0.052)\end{array}$ & $\begin{array}{c}0.926 \\
(0.047)\end{array}$ \\
\hline
\end{tabular}

Note: Data are drawn from the DHS. Means are population weighted. Wealth percentiles are created at the household level. The correlation coefficient is that between the joint probability and the relevant undernutrition rate from Table 1. Elasticities estimated by double-log regression. Robust standard errors in parentheses. 
Table 8: Nutritional outcomes within the household by gender and nutritional status of the head

\begin{tabular}{|c|c|c|c|c|c|c|c|c|c|c|}
\hline & \multicolumn{2}{|c|}{ Male head is underweight } & \multicolumn{2}{|c|}{$\begin{array}{l}\text { Male head is not } \\
\text { underweight }\end{array}$} & \multicolumn{2}{|c|}{$\begin{array}{c}\text { Female head is } \\
\text { underweight }\end{array}$} & \multicolumn{2}{|c|}{$\begin{array}{c}\text { Female head is not } \\
\text { underweight }\end{array}$} & \multicolumn{2}{|c|}{ All households } \\
\hline & Mean & Variance & Mean & Variance & Mean & Variance & Mean & Variance & Mean & Variance \\
\hline Ethiopia & 0.649 & 0.163 & 0.192 & 0.105 & 0.773 & 0.112 & 0.161 & 0.084 & 0.338 & 0.106 \\
\hline Ghana & 0.684 & 0.125 & 0.051 & 0.032 & 0.731 & 0.129 & 0.049 & 0.027 & 0.098 & 0.039 \\
\hline Lesotho & 0.680 & 0.132 & 0.070 & 0.044 & 0.784 & 0.095 & 0.075 & 0.042 & 0.155 & 0.057 \\
\hline Namibia & 0.676 & 0.131 & 0.064 & 0.040 & 0.651 & 0.148 & 0.112 & 0.065 & 0.161 & 0.064 \\
\hline Rwanda & 0.531 & 0.186 & 0.123 & 0.077 & 0.673 & 0.146 & 0.144 & 0.078 & 0.171 & 0.082 \\
\hline Senegal & 0.533 & 0.183 & 0.174 & 0.110 & 0.555 & 0.172 & 0.201 & 0.120 & 0.231 & 0.120 \\
\hline Sierra Leone & 0.523 & 0.180 & 0.114 & 0.074 & 0.564 & 0.172 & 0.112 & 0.070 & 0.150 & 0.079 \\
\hline Mean & 0.628 & 0.162 & 0.126 & 0.075 & 0.732 & 0.124 & 0.121 & 0.068 & 0.219 & 0.083 \\
\hline
\end{tabular}

Note: Data are drawn from DHSs that collected BMI for male adults as well as for women and children. Statistics are population weighted. Each household member is assigned a value of 1 if he or she is either underweight for adults or stunted or wasted if they are children and zero if the member is not

undernourished. Mean undernourished refers to the average rate of undernourishment within the household. The variance is calculated within the household using the variance formula for the Bernoulli distribution, $\bar{x}(1-\bar{x})$. 
Table 9: Conditional probabilities with and without intrahousehold inequality for poorest $20 \%$ of households

\begin{tabular}{|c|c|c|c|c|c|c|c|c|c|}
\hline & \multicolumn{4}{|c|}{$\begin{array}{l}\text { Underweight } \\
\text { Simulated without intra- } \\
\text { household inequality }\end{array}$} & \multicolumn{2}{|c|}{$\begin{array}{l}\text { Stunted } \\
\text { Simulated without intra- } \\
\text { household inequality }\end{array}$} & \multicolumn{3}{|c|}{$\begin{array}{l}\text { Wasted } \\
\text { Simulated without intra- } \\
\text { household inequality }\end{array}$} \\
\hline & Actual & $\begin{array}{c}\text { Regular } \\
\text { cutoff }\end{array}$ & New cutoff & Actual & $\begin{array}{c}\text { Regular } \\
\text { cutoff }\end{array}$ & New cutoff & Actual & $\begin{array}{c}\text { Regular } \\
\text { cutoff }\end{array}$ & New cutoff \\
\hline \multicolumn{10}{|l|}{ Poorest 20\% } \\
\hline Ethiopia & 0.225 & 0.232 & 0.231 & 0.271 & 0.273 & 0.270 & 0.287 & 0.295 & 0.298 \\
\hline Ghana & 0.375 & 0.399 & 0.441 & 0.445 & 0.420 & 0.454 & 0.343 & 0.320 & 0.299 \\
\hline Lesotho & 0.243 & 0.279 & 0.295 & 0.361 & 0.357 & 0.349 & 0.395 & 0.528 & 0.478 \\
\hline Namibia & 0.292 & 0.362 & 0.368 & 0.381 & 0.434 & 0.419 & 0.387 & 0.293 & 0.356 \\
\hline Rwanda & 0.235 & 0.241 & 0.239 & 0.272 & 0.278 & 0.272 & 0.256 & 0.274 & 0.216 \\
\hline Senegal & 0.184 & 0.255 & 0.239 & 0.318 & 0.376 & 0.364 & 0.224 & 0.286 & 0.242 \\
\hline Sierra Leone & 0.203 & 0.287 & 0.273 & 0.253 & 0.254 & 0.253 & 0.182 & 0.160 & 0.177 \\
\hline Mean & 0.228 & 0.253 & 0.258 & 0.291 & 0.294 & 0.293 & 0.270 & 0.276 & 0.269 \\
\hline \multicolumn{10}{|l|}{ Poorest 40\% } \\
\hline Ethiopia & 0.454 & 0.486 & 0.485 & 0.527 & 0.533 & 0.519 & 0.591 & 0.619 & 0.608 \\
\hline Ghana & 0.621 & 0.634 & 0.677 & 0.708 & 0.698 & 0.711 & 0.489 & 0.453 & 0.443 \\
\hline Lesotho & 0.521 & 0.566 & 0.573 & 0.617 & 0.614 & 0.617 & 0.588 & 0.668 & 0.600 \\
\hline Namibia & 0.499 & 0.579 & 0.586 & 0.652 & 0.685 & 0.656 & 0.579 & 0.483 & 0.562 \\
\hline Rwanda & 0.455 & 0.488 & 0.481 & 0.525 & 0.533 & 0.523 & 0.495 & 0.538 & 0.498 \\
\hline Senegal & 0.380 & 0.495 & 0.472 & 0.589 & 0.624 & 0.636 & 0.468 & 0.508 & 0.533 \\
\hline Sierra Leone & 0.394 & 0.528 & 0.509 & 0.491 & 0.495 & 0.484 & 0.417 & 0.442 & 0.481 \\
\hline Mean & 0.449 & 0.503 & 0.503 & 0.545 & 0.550 & 0.542 & 0.526 & 0.549 & 0.547 \\
\hline
\end{tabular}

Note: Data are drawn from DHSs that collected BMI for male adults as well as for women and children. Actual refers to the incidence of undernourishment in the population. To simulate the results without intra-household inequality, all individuals are assigned the household's average value of BMI, height-for-age and weight-for-height for adults and children respectively. With the "regular" cutoff, individuals are assigned to be underweight, stunted, and wasted if this value is below 18.5 for BMI and -2 for height-for-age and weight-for-height. With the "new cutoff”, a cutoff point for undernourishment is chosen in order to minimize the difference between average undernourishment and simulated nourishment. This cutoff is always above that of the standard cutoff points. Wealth percentiles are at the household level. Statistics are population weighted. 
Table 10: Conditional probabilities for underweight women using predicted wealth from the augmented regressions

\begin{tabular}{|c|c|c|c|c|}
\hline & \multicolumn{2}{|c|}{ Model 1} & \multicolumn{2}{|c|}{ Model 2} \\
\hline & Bottom 20\% & Bottom $40 \%$ & Bottom 20\% & Bottom $40 \%$ \\
\hline Benin & 0.271 & 0.482 & 0.369 & 0.620 \\
\hline Burkina Faso & 0.351 & 0.597 & 0.368 & 0.610 \\
\hline Burundi & 0.287 & 0.562 & 0.318 & 0.579 \\
\hline Cameroon & 0.494 & 0.746 & 0.481 & 0.749 \\
\hline Congo & 0.287 & 0.537 & 0.358 & 0.631 \\
\hline Cote D'Ivoire & 0.254 & 0.459 & 0.346 & 0.569 \\
\hline DRC & 0.389 & 0.654 & 0.416 & 0.669 \\
\hline Ethiopia & 0.283 & 0.515 & 0.302 & 0.511 \\
\hline Gabon & 0.228 & 0.513 & 0.433 & 0.755 \\
\hline Gambia & 0.293 & 0.528 & 0.389 & 0.618 \\
\hline Ghana & 0.374 & 0.624 & 0.447 & 0.673 \\
\hline Guinea & 0.314 & 0.553 & 0.326 & 0.575 \\
\hline Kenya & 0.363 & 0.629 & 0.389 & 0.654 \\
\hline Lesotho & 0.408 & 0.601 & 0.484 & 0.639 \\
\hline Liberia & 0.301 & 0.530 & 0.350 & 0.612 \\
\hline Malawi & 0.302 & 0.514 & 0.378 & 0.572 \\
\hline Mali & 0.274 & 0.490 & 0.314 & 0.541 \\
\hline Mozambique & 0.303 & 0.565 & 0.365 & 0.591 \\
\hline Namibia & 0.350 & 0.589 & 0.397 & 0.667 \\
\hline Niger & 0.320 & 0.582 & 0.379 & 0.630 \\
\hline Nigeria & 0.335 & 0.577 & 0.418 & 0.682 \\
\hline Rwanda & 0.327 & 0.584 & 0.402 & 0.608 \\
\hline Senegal & 0.307 & 0.537 & 0.376 & 0.629 \\
\hline Sierra Leone & 0.280 & 0.510 & 0.333 & 0.577 \\
\hline Swaziland & 0.354 & 0.588 & 0.451 & 0.759 \\
\hline Tanzania & 0.346 & 0.587 & 0.360 & 0.601 \\
\hline Togo & 0.399 & 0.652 & 0.388 & 0.645 \\
\hline Uganda & 0.406 & 0.636 & 0.380 & 0.629 \\
\hline Zambia & 0.325 & 0.549 & 0.331 & 0.573 \\
\hline Zimbabwe & 0.343 & 0.585 & 0.432 & 0.635 \\
\hline Mean & 0.322 & 0.562 & 0.369 & 0.611 \\
\hline
\end{tabular}

Note: Data are drawn from DHSs. Means are population weighted. The table gives the proportions of underweight women who fall into the poorest 20 and $40 \%$ of the distribution of predicted values from regressions of log BMI on wealth, and additional household and individual covariates. For example, $27.1 \%$ of underweight women in Benin have predicted BMI values that fall into the bottom $20 \%$ of all predicted values for women. 


\section{Table 11: Conditional probabilities for undernourished children using predicted wealth from the augmented regressions}

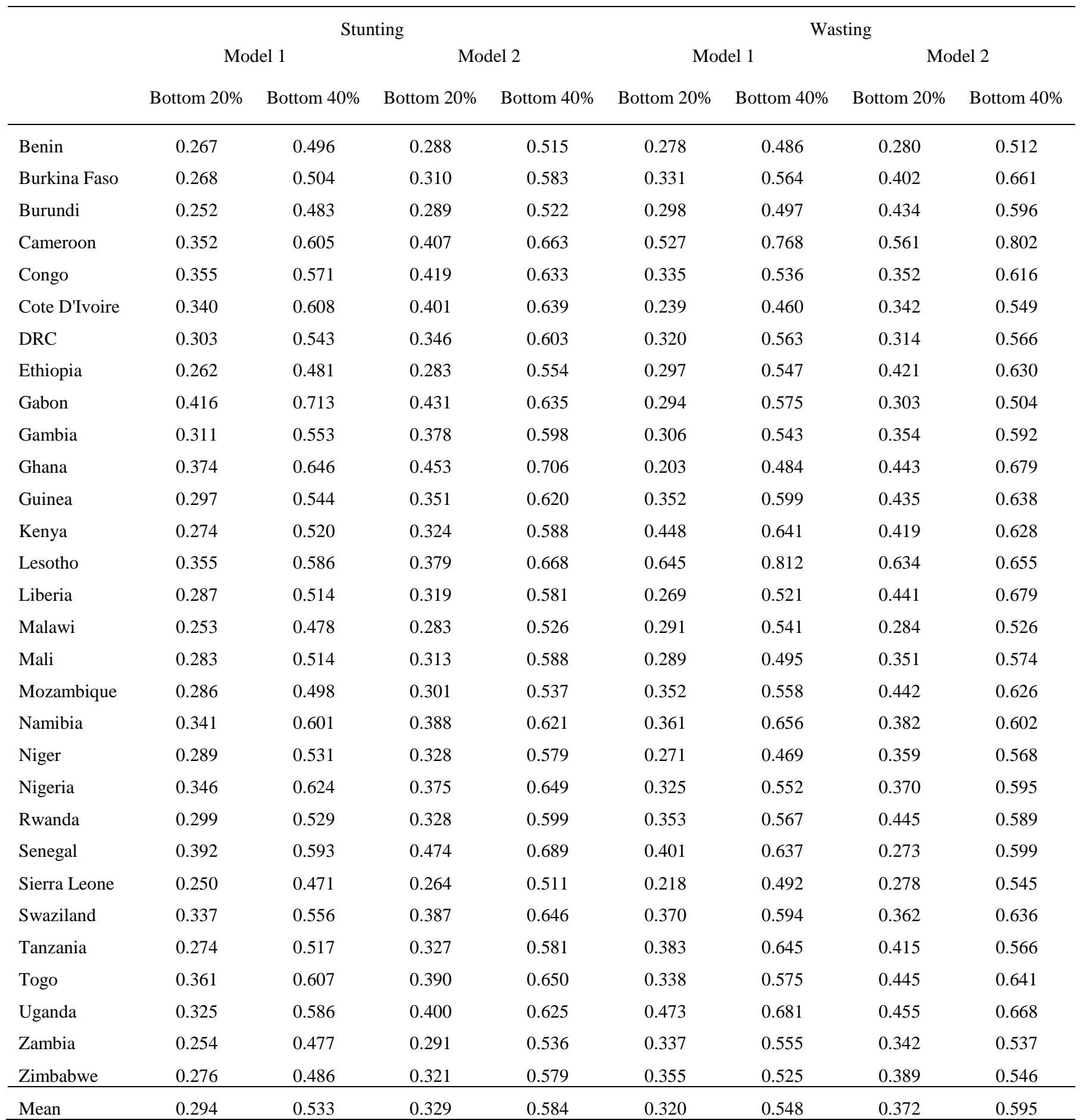

Note: Data are drawn from DHSs. Means are population weighted. The table gives the proportions of stunted and wasted children who fall into the poorest 20 and $40 \%$ of the distribution of the predicted values from regressions height-for-age and weight-for-height on wealth, and additional household and individual covariates. For example, $26.7 \%$ of stunted children in Benin have predicted values that fall into the bottom $20 \%$ of all predicted values for children in the Model (2) regression with height-for-age as the dependent variable. 